\title{
Remote and Proximal Sensing-Derived Spectral Indices and Biophysical Variables for Spatial Variation Determination in Vineyards
}

\author{
Nicoleta Darra 1, Emmanouil Psomiadis 2,*(D), Aikaterini Kasimati ${ }^{1}$, Achilleas Anastasiou ${ }^{1}$, \\ Evangelos Anastasiou ${ }^{1}$ and Spyros Fountas ${ }^{1}$
}

1 Laboratory of Agricultural Machinery, Department of Natural Resources Management and Agricultural Engineering, School of Environment and Agricultural Engineering, Agricultural University of Athens, 75 Iera Odos Str., Votanikos, 11855 Athens, Greece; nicoletadarra@aua.gr (N.D.); akasimati@aua.gr (A.K.); lmac4ana@aua.gr (A.A.); evangelos_anastasiou@aua.gr (E.A.); sfountas@aua.gr (S.F.)

2 Laboratory of Mineralogy and Geology, Department of Natural Resources Management and Agricultural Engineering, School of Environment and Agricultural Engineering, Agricultural University of Athens, 75 Iera Odos Str., Votanikos, 11855 Athens, Greece

* Correspondence: mpsomiadis@aua.gr; Tel.: +30-2105294156

check for updates

Citation: Darra, N.; Psomiadis, E.; Kasimati, A.; Anastasiou, A.; Anastasiou, E.; Fountas, S. Remote and Proximal Sensing-Derived Spectral Indices and Biophysical Variables for Spatial Variation Determination in Vineyards. Agronomy 2021, 11, 741. https:// doi.org/10.3390/agronomy11040741

Academic Editor: Gabriele Cola

Received: 2 March 2021

Accepted: 9 April 2021

Published: 11 April 2021

Publisher's Note: MDPI stays neutral with regard to jurisdictional claims in published maps and institutional affiliations.

Copyright: (c) 2021 by the authors. Licensee MDPI, Basel, Switzerland. This article is an open access article distributed under the terms and conditions of the Creative Commons Attribution (CC BY) license (https:// creativecommons.org/licenses/by/ $4.0 /)$

\begin{abstract}
Remote-sensing measurements are crucial for smart-farming applications, crop monitoring, and yield forecasting, especially in fields characterized by high heterogeneity. Therefore, in this study, Precision Viticulture (PV) methods using proximal- and remote-sensing technologies were exploited and compared in a table grape vineyard to monitor and evaluate the spatial variation of selected vegetation indices and biophysical variables throughout selected phenological stages (multi-seasonal data), from veraison to harvest. The Normalized Difference Vegetation Index and the Normalized Difference Red-Edge Index were calculated by utilizing satellite imagery (Sentinel-2) and proximal sensing (active crop canopy sensor Crop Circle ACS-470) to assess the correlation between the outputs of the different sensing methods. Moreover, numerous vegetation indices and vegetation biophysical variables (VBVs), such as the Modified Soil Adjusted Vegetation Index, the Normalized Difference Water Index, the Fraction of Vegetation Cover, and the Fraction of Absorbed Photosynthetically Active Radiation, were calculated, using the satellite data. The vegetation indices analysis revealed different degrees of correlation when using diverse sensing methods, various measurement dates, and different parts of the cultivation. The results revealed the usefulness of proximal- and remote-sensing-derived vegetation indices and variables and especially of Normalized Difference Vegetation Index and Fraction of Absorbed Photosynthetically Active Radiation in the monitoring of vineyard condition and yield examining, since they were demonstrated to have a very high degree of correlation (coefficient of determination was 0.87 ). The adequate correlation of the vegetation indices with the yield during the latter part of the veraison stage provides valuable information for the future estimation of production in broader areas.
\end{abstract}

Keywords: precision viticulture; Sentinel-2; crop circle ACS-470; vegetation indices; vegetation biophysical variables

\section{Introduction}

Grapevines are one of the most important planted fruit crops, with a significant position in human sustenance. More than seven million hectares of vineyards are grown worldwide in many different geographical areas [1] and are commonly characterized by high heterogeneity, due to physical, biological, and chemical factors, including spatial variations in topography, climatic conditions, and soil characteristics, as well as nonstructural factors, mediated by crop practices $[2,3]$.

Precision agriculture and farm management necessitate monitoring of crops at high spatial and frequent temporal resolution during the entire growing season [4]. Precision 
Viticulture (PV) is considered as the use of Precision Agriculture (PA) in vineyards and regularly aims at developing variance management to attain the actual requirements of each area [5,6]. Over the last decades, PV has emerged as an innovation-driven solution and received significant attention in the agricultural community [7-9].

Remote and proximal sensing (RS and PS) have been proven to be important tools in PV for crop-condition monitoring, yield prediction, and optimization of agricultural management [10-14]. These remote and proximal sensors take advantage of vegetation's reflectance properties and provide the possibility to assess crop parameters (e.g., biomass, yield, acreage, and vegetation vigor) and predict crop conditions or yield, enabling early and efficient decision making in fertilization, irrigation and pest controlling $[2,15,16]$.

Remote and proximal applications in PA go back to the middle 1980s with the treatment of satellite, aerial, and hand-held or tractor-mounted sensors, using mainly of the visible and near-infrared parts of the electromagnetic spectrum [17]. Typically, remote sensing provided systematic information for large areas instead of proximal sensing, which was primarily used for minor scale applications (one or few parcels) with higher resolution. Most of the initial research on vineyards using remote sensing has involved the analysis of multispectral satellite or aerial images such as those of Lamb et al. [18], Belmonte et al. [4], Meggio et al. [19]. The last two decades, the launch of enhanced satellite systems (like GeoEye, WorldView, Pléiades, Cartosat, etc.) and Unmanned Aerial Vehicles (UAV) deliver new perspectives in PA. They carry innovative acquisition instruments (LiDAR, thermal cameras, etc.) having extremely enhanced spectral (using wavelengths from the ultraviolet to thermal infrared and microwave portions and smaller bandwidths of hyperspectral sensing), spatial (reaches the few meters or centimeters), and temporal (few days acquisition) resolutions, which offer a considerable development at a more accurate and near-realtime crop management $[17,20]$. Additionally, the full and free availability of satellite data has accelerated an increase of interest in the use of Earth Observation (EO) products in agriculture. Copernicus program of the European Space Agency (ESA) offers accurate, timely, and open-access data to enhance the monitoring and management of agricultural land. The Sentinel-2 (S2) mission comprises two identical satellites in the same orbit, $180^{\circ}$ apart. Together they cover all Earth's surface, with a wide swath coverage (290 km width), providing imagery of high spatial $(10 \mathrm{~m})$, spectral (13 bands), and temporal (5-day cycle, at the equator) resolution, providing new perspectives for the exploration and monitoring of crops [21-24]. Moreover, multi-seasonal imagery offers a spatially detailed and up-to-date geo-information, which is unique for crop monitoring, covering all the growing stages and different conditions of the cultivation $[25,26]$.

Proximal sensing provides a great amount of accurate data, that under the appropriate elaboration can produce very reliable and extremely useful predictive maps $[10,27]$. The technology of active proximal sensors, such as the active crop canopy sensor Crop Circle (CC) ACS-470 (Holland Scientific Inc., Lincoln, NE, USA) which was used in this research, has the key advantage of carrying their own light source and, therefore, are able to overcome numerous restrictions associated with satellite or airborne remote sensing [28-30]. These limitations include adverse weather conditions, atmospheric effects, and potential revisit time. Proximal sensors decrease the distance between the light source and the target and can be guided towards the desired canopy part; therefore, they reduce the effect of shadows, minimize the background soil interferences, and enhance the sensing potential [31]. Crop Circle ACS-470 and the previous versions (210 and 430) have been utilized in numerous studies associated with PV [31-33] and other crops, such as rice, maize, wheat, etc. [34-36].

Consequently, the use of the recent and innovative satellite and proximal products has released several new perspectives on the potential use in PV [10,37]. Many research plans concerning PV worldwide exploit a wide range of available remote and proximal-sensing technologies to describe the vineyard spatial and temporal variability, revealing the significant value of proximal, aerial and satellite sensors [15,38-40]. Both sensor systems utilized in this study, Crop Circle and Sentinel-2, can retrieve multiple-wave-band data representing canopy reflectance enabling field variability detection and vineyard vigor monitoring and 
can be transformed subsequently into many potential spectral vegetation indices (VIs) and vegetation biophysical variables (VBVs) [41]. VIs and VBVs are important parameters and, therefore, are unique to assess variations in the physiological state and biophysical properties of vegetation. Moreover, they perform crop growth monitoring and yield assessment, detect vegetation stress, and improve crop management practices [19,31,42]. The optimal wavelengths and VIs vary for different crop biophysical parameters and growth stages (GSs). These indices have been widely implemented within remote-sensing applications by using different remote- and proximal-sensing platforms [13,17]. The Normalized Difference Vegetation Index (NDVI) is the most used vegetation index that measures the difference between the canopy reflectance in the near-infrared and visible bands [43,44]. Moreover, numerous innovative and intriguing VIs and VBVs such as the Normalized Difference RedEdge Index (NDRE), the Modified Soil Adjusted Vegetation Index (MSAVI), the Normalized Difference Water Index (NDWI), the Fraction of Vegetation Cover (FVC) and the Fraction of Absorbed Photosynthetically Active Radiation (FAPAR) have been developed which are related to the vigorous, photosynthetically active radiation absorbed by the greener and healthier leaves. Therefore, are considered as a unique implement to interpret the spatial patterns of the canopy such as changes in canopy size, photosynthetic capacity and canopy chlorophyll content, structure and plant health status, crop productivity, nutrient or water stress and berry characteristics which can be related to changes in microclimate or other conditions [19,20,29,31,45-48].

The research occurred in a trial vineyard in the Prefecture of Corinth in Peloponnese (Southern Greece). The Peloponnese wine region is the largest vineyard area in Greece, constituting around $31 \%$ of wine production in the country and covering an area of approximately 22,000 ha [49].

Numerous studies the last few decades have tried to connect the characteristics of the vegetation with the yield, in vineyards, in order to estimate their potential productivity, such as those conducted by Borgogno-Mondino et al. [46], Matese and Di Gennaro [2], Dobrowski et al. [50], Ballesteros et al. [51], etc. Nevertheless, the lack of plenty of studies considering table grapes instead of the most frequent examination of wine grapes, as well as the combination of remote and proximal sensing and the assessment of several VIs and VBVs reveals the importance of the present research.

This study aimed to (a) compare and evaluate proximal- and satellite-derived data; and (b) monitor and describe the temporal and spatial variability of spectral and canopybased vegetation characteristics within a vineyard and their relation to productivity, using different sensors, in various growth stages. In this context, a comparison of NDVI and NDRE derived both from remote- and proximal-sensing data sources, for the different data-sources comparison, and additionally, MSAVI, NDWI, FVC, and FAPAR derived only from remote-sensing data for the assessment of their correlation with the vineyard yield, were carried out at four different stages of the cultivation. The analysis considered the heterogeneity of the data regarding the spatial, temporal, and spectral resolution, to avoid accuracy problems.

\section{Materials and Methods}

\subsection{Study Area}

The study area is situated in the prefecture of Corinth (Peloponnese) in Southern Greece $\left(37^{\circ} 54.532^{\prime}\right.$ N, $22^{\circ} 44.798^{\prime}$ E, Figure $\left.1 \mathrm{a}, \mathrm{b}\right)$, which is characterized by a dry Mediterranean climate with hot summers and mild winters, and according to the Köppen-Geiger climate allocation, it is classified as $\mathrm{Csa}$, with an average annual temperature of $18{ }^{\circ} \mathrm{C}$ and rainfall of 550-600 $\mathrm{mm}$ [52]. 

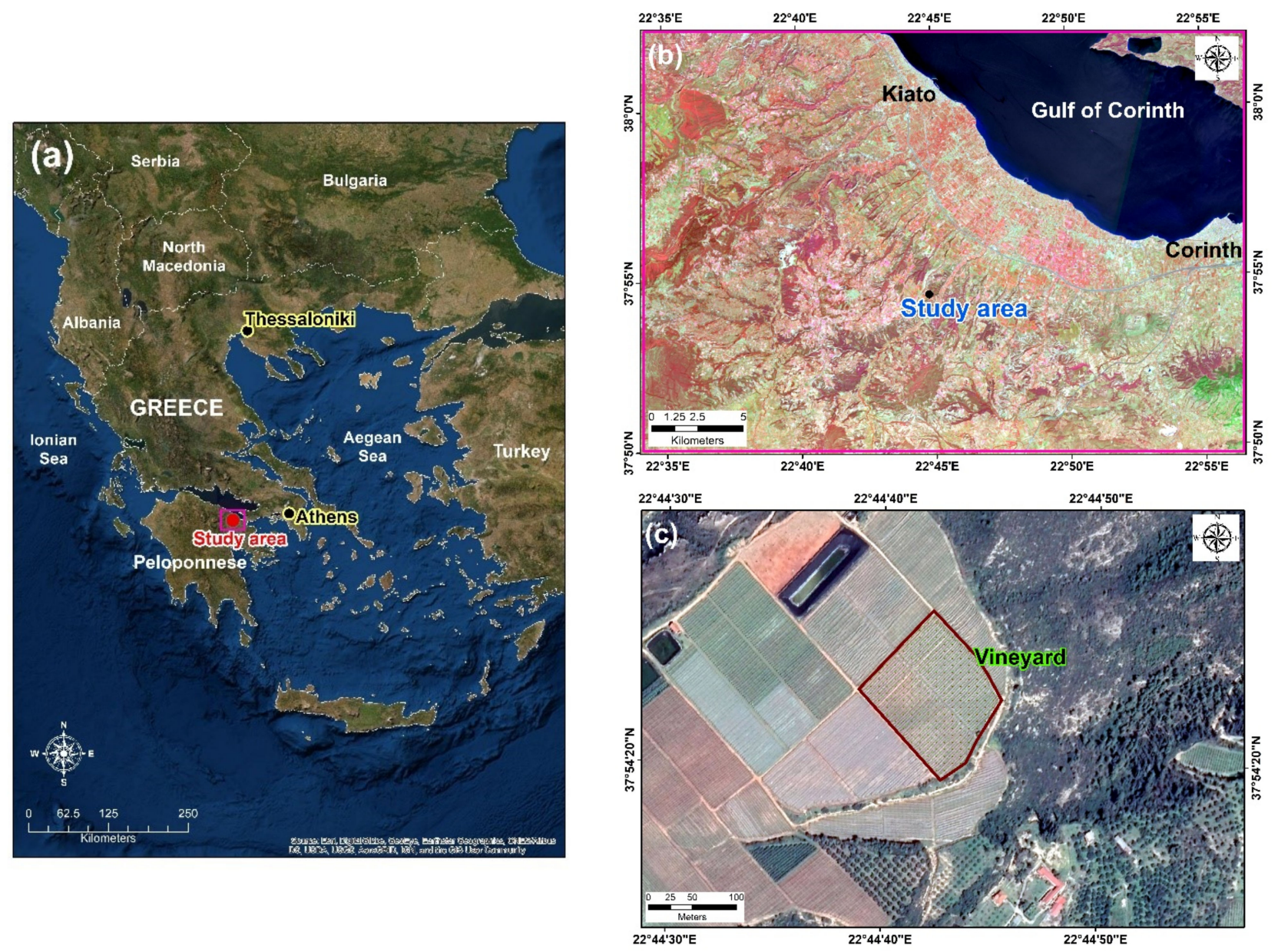

Figure 1. (a) The national, (b) regional, and (c) local position of the experimental vineyard field.

The experimentation was conducted during 2017, in a 1.4-hectare vineyard (Figure 1c). The vines were planted in 2006 with Vitis vinifera L. cv. Thompson seedless, and the variety was grafted onto a 1103 Paulsen rootstock system, having a double cross-arm trellis ordinance with $1.8 \mathrm{~m}$ and $2.6 \mathrm{~m}$ among the stems and the lines, respectively. Typical canopy management and configuration processes, growth regulators, irrigation water (about $2400 \mathrm{~mm} / \mathrm{ha}$ ), and fertilizers (sixteen foliar applications) were applied during the growing season to achieve profitable conditions for grape diameter and sugar content. Besides, soil physical and chemical properties, such as texture, electric conductivity, $\mathrm{pH}$, organic matter, etc., were measured. The plot displays an average elevation difference of 15-20 m, which is a little higher in the western-northwestern part (Figure 2a) and shows a variance in soil composition, with mainly two different soil types, sandy loam (west and southwest part) and clay-clay loam (east and northeast part; Figure 2b), as well as a small difference in the content of iron ions, as it is higher at the western part. 


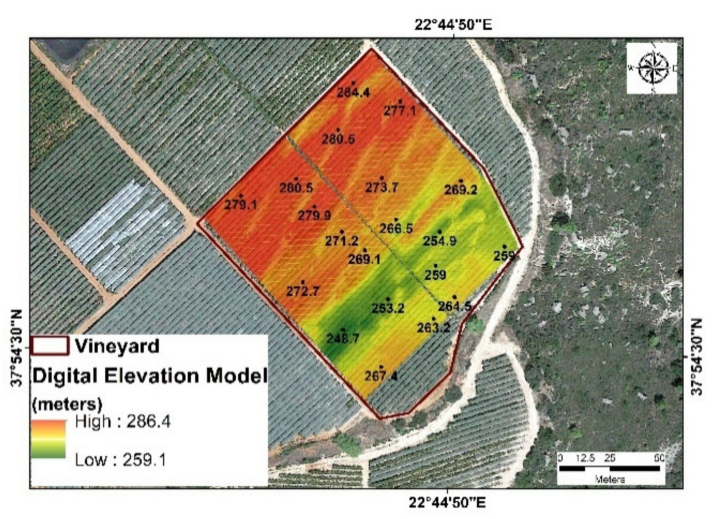

(a)

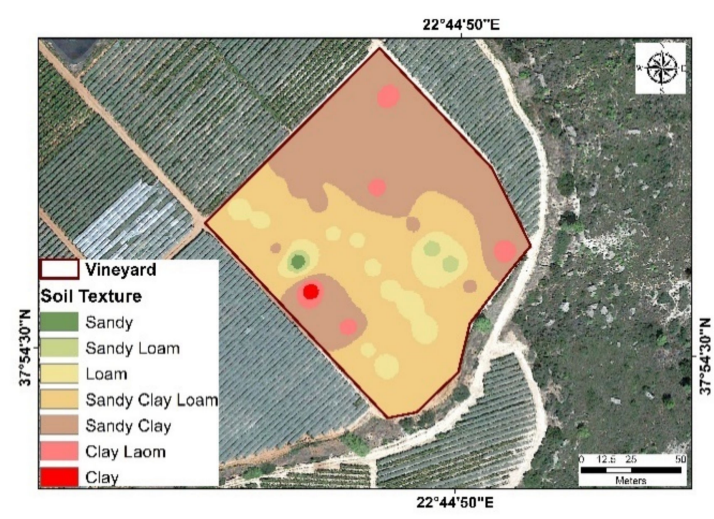

(b)

Figure 2. (a) Very high-resolution Digital Elevation Model and (b) soil texture distribution characteristics of the experimental vineyard field.

\subsection{Datasets and Methodology}

\subsubsection{Proximal and Remote-Sensing Data}

Sentinel-2 satellite system carries a Multi-Spectral Imager (MSI) sensor which covers the Visible (VIS), Near Infrared (NIR), and Short-Wave Infrared (SWIR) portions of the electromagnetic spectrum. Five clouds free and atmospherically corrected (2A) images to provide Bottom of Atmosphere reflectance values in cartographic geometry (UTM/WGS84 projection), were acquired free of charge via the ESA portal (https://scihub.copernicus.eu/ accessed on 13 October 2020), for the monitoring of the study area.

The data preprocessing comprised image resampling to $10 \mathrm{~m}$, since $\mathrm{S} 2$ spectral bands operate on the different spatial resolution of 10 (4 bands, B2, B3, B4, and B8), $20 \mathrm{~m}$ (6 bands, B5, B6, B7, B8A, B11, and B12), and $60 \mathrm{~m}$ (3 bands, B1, B9, and B10). Furthermore, given the small size of the study area, a subset and masking of the pixels outside the vineyard boundaries were applied. Finally, the collocation of 10 spectral bands (by excluding bands 1 (coastal aerosol), 9 (water vapor), and 10 (cirrus)) and four supplementary products of the atmospherically corrected images for each date was made [53]. The four supplementary are related to the directional information, including sun zenith (angle $\theta_{\mathrm{s}}$ ), sun azimuth (angle $\varphi$ ), view zenith mean, and view azimuth mean, which are necessary for the calculation of the VBVs (FVC and FAPAR).

The proximal measurements were conducted with a Crop Circle ACS-470 (Holland Scientific Inc., Lincoln, NE, USA) active sensor, which incorporates three optical measurement channels and is user-configurable from 440 to $800 \mathrm{~nm}$, using $12.5 \mathrm{~mm}$ interference filters (Figure 3a). This sensor is widely used for numerous Precision Agriculture applications to record a variety of vegetation indices [30]. The CC ACS-470 provides six spectral bands. In this study, three spectral bands were chosen and configured based on literature reviews and previous research, having as the main objective to be in conjunction with the corresponding bands of S2. Thus, the selected bands cover the red $(670 \mathrm{~nm})$, red edge $(730 \mathrm{~nm})$, and NIR $(760 \mathrm{~nm})$ parts of the electromagnetic spectrum [30,34]. The CC sensor was adapted to a special construction mounted on a quad bike, together with a Garmin GPS16X HVS, (Garmin, Olathe, KS, USA) to georeference the data (Figure 3b). 


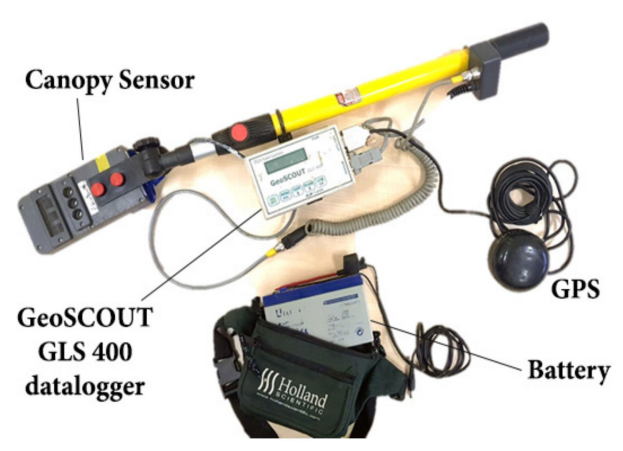

(a)

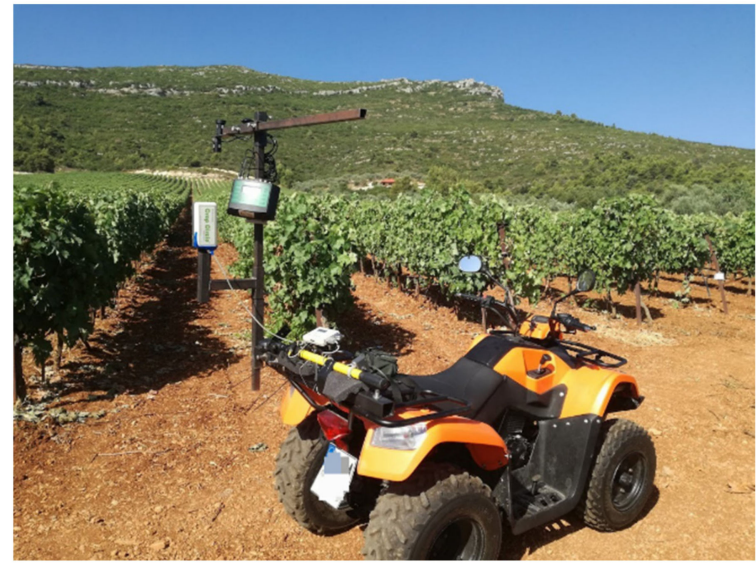

(b)

Figure 3. (a) The Crop Circle ACS-470 parts, and (b) the Crop Circle canopy sensor, along with the vehicle and the special adaptation construction, for the measurements in the field.

The measurements were collected approximately $1.5 \mathrm{~m}$ above the soil surface and $1 \mathrm{~m}$ away from the side canopy area, at a rate of 10 readings per second and walking at a constant speed. Spectral-reflectance data were recorded and saved as a text file on an SD flashcard, using the Holland Scientific GeoSCOUT GLS-400 data logger (Figure 3a). A critical step before the analysis was the removal of artifacts within the data that may occur as extraneous data points that lie outside the general range of the dataset (termed outliers), or as data values that differ significantly from neighboring data values but lie within the general range of the data (termed inliers). A protocol on data trimming that was proposed by Taylor et al. [54] was used to ensure the robustness of the analysis and to yield accurate conclusions.

Reflectance data of CC and S2 were collected across the field at three different growth stages divided into five parts (Table 1 and Figure 4): (i) start of veraison (SV); (ii) mid of veraison, which is separated into two parts, MV-1 and MV-2; and (iii) technological maturity, which is also separated into two parts, H-1 and H-2. The processing stage that called veraison (derived from the French expression "verr-ray-zohn") is one of the most important moments in a grapevine's annual lifecycle is the onset of ripening when the grapes turn from green to red and naturally begin to sweeten $[18,55,56]$. The choice of these concreteness growth stages was made considering that there is a rapid change in berry composition, which is reproduced to the final yield and quality $[27,38]$. The proximalsensing measurements' dates occurred as close as possible to the dates of the satellite products (Table 1 and Figure 4 ).

Table 1. Acquisition dates of satellite and proximal-sensing data.

\begin{tabular}{ccc}
\hline Growth Stages & Proximal-Sensing Dates & Satellite-Sensing Dates \\
\hline SV & 15 June 2017 & 15 June 2017 \\
MV-1 & 22 June 2017 & 25 June 2017 \\
MV-2 & 09 July 2017 & 05 July 2017 \\
H-1 & 26 July 2017 & 25 July 2017 \\
H-2 & 16 August 2017 & 14 August 2017 \\
\hline
\end{tabular}

SV, start of veraison; MV-1, mid of veraison, part 1; MV-2, mid of veraison, part 2; H-1, technological maturity, part $1 ; \mathrm{H}-2$, technological maturity, part 2. 


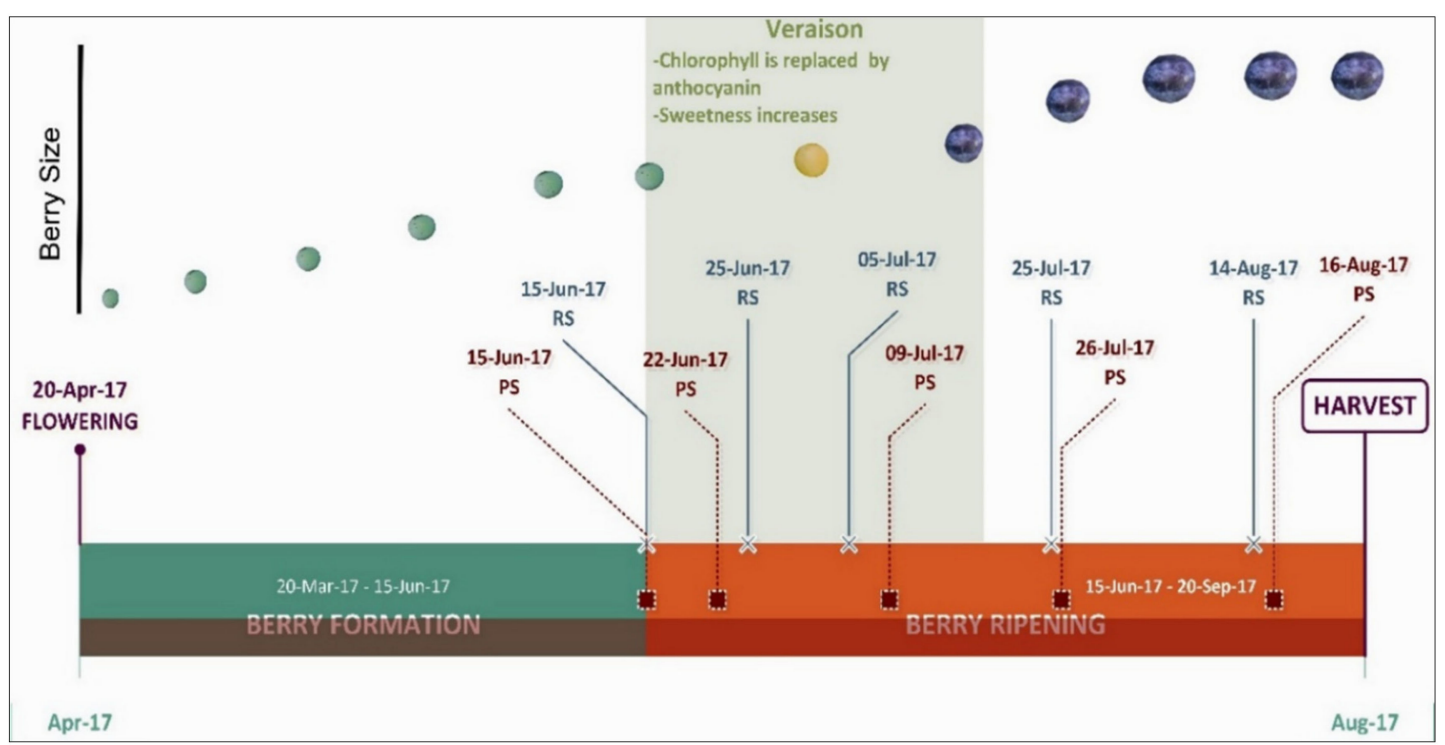

Figure 4. Temporal distribution of the proximal- and remote-sensing data during the vineyard growing period.

\subsubsection{Spectral Characteristics of Vegetation Indices and Vegetation Biophysical Variables}

For the spatial variation comparison of proximal and satellite systems and their relation to the yield, four VIs, and two VBVs were examined. As far as it concerns the VIs, the most commonly used vegetation index, NDVI, and the innovative and intriguing calculations of NDRE, MSAVI, and NDWI were computed [13,33,57-59].

NDVI discriminates the different response of vegetation to the visible and nearinfrared part of the electromagnetic spectrum that is closely related to crop status (Equation (1)) [2,43]. It takes advantage of the strong energy absorption by the chlorophyll in the red portion of the spectrum (RED), and on the high energy scattering by the internal structure of leaves in the near-infrared (NIR) part. It displays a sensitive response to green vegetation even for low vegetation-covered areas and is related to canopy structure and photosynthesis. Though, NDVI is sensitive to the effects of soil brightness and cloud or canopy shadow. The result of NDVI calculation is an image with a continuum of pixel values that range from -1 to 1 , where, in general terms, negative values correspond to non-vegetated surfaces, while positive values correspond to vegetated ones, and where higher values are related to healthy photosynthetic vegetation, while lower values, especially those $<0.2$, are related to stressed vegetation or bare soil [21,60]. Considering that the NIR band 8 of S2 has a different wavelength range from the NIR band that is available from the CC sensor, the S2-NDVI was calculated by using the spectral band 6, which represents reflectance from radiation at $740 \mathrm{~nm}$, very close to the recorded wavelength of the CC NIR band $(730 \mathrm{~nm})$.

NDRE is a narrowband greenness VI that was designed to provide a measure of the overall amount and quality of photosynthetic material in vegetation, which is essential for understanding the state of vegetation. Narrowband greenness VIs are considered ideal for use with imaging spectrometers. NDRE was measured by using the NIR and red-edge band (RE; $705 \mathrm{~nm}$ ), where RE replaces the red band in the equation of NDVI (Equation (2)) [61]. Compared with NDVI, the NDRE index as a widely used red-edge-based VI has been proved to be more resistant to the saturation problem and is more sensitive than NDVI to chlorophyll content in vegetation $[33,62,63]$.

Modified Soil Adjusted Vegetation Index 2 (MSAVI2) is a soil adjusted vegetation index that aims to overcome some of the constraints of NDVI when applied to crops with a medium or high exposure of soil surface (Equation (3)). Moreover, the use of MSAVI2 avoids the main problem of the original soil-adjusted vegetation index, which is required to specify the soil-brightness correction factor $(\mathrm{L})$ through trial-and-error, based on the amount 
of vegetation in the study area. Qi et al. [64] determined the MSAVI2, which eliminates the need to find the soil line from a feature-space plot or even explicitly specify the soil brightness correction factor. Likewise, it has a simpler algorithm, and it is mainly used in the analysis of plant growth, yield estimation, and Leaf Area Index (LAI) assessment.

NDWI is delineated from the combination of NIR and SWIR reference units which are sensing similar depths through vegetation canopies (Equation (4)) [65]. It is sensitive to changes in vegetation water content and less sensitive to atmospheric aerosol scattering effects. High NDWI values demonstrate a high-water content of the vegetation.

Concerning the VBVs, the FVC and FAPAR biophysical parameters were estimated. FVC defines the ratio of the vertical projected area of vegetation canopy to the reference ground surface, expressed as a fraction $[47,66]$. FVC is a key variable related to many biophysical features, such as plant phenology, density, and yield [47,67]. FAPAR corresponds to the fraction of photosynthetically active radiation (i.e., within 400 to $700 \mathrm{~nm}$ ) absorbed by the green parts of the canopy, and it is, consequently, an indicator of the status of the vegetation canopy, since the absorption of the photosynthetically active radiation is related to leaf chlorophyll content $[45,68]$. FVC and FAPAR calculation require the reflectance of 8 simulated bands $\left(B_{3}-B_{7}, B_{8 A}, B_{11}\right.$, and $\left.B_{12}\right)$ and the cosine of three angles (solar zenith angle, view zenith angle, and relative azimuth angle between solar and view).

$$
\begin{aligned}
\text { NDVI } & =\frac{\left(\mathrm{B}_{6}-\mathrm{B}_{4}\right)}{\left(\mathrm{B}_{6}+\mathrm{B}_{4}\right)} \\
\text { NDRE } & =\frac{\left(\mathrm{B}_{8}-\mathrm{B}_{5}\right)}{\left(\mathrm{B}_{8}+\mathrm{B}_{5}\right)} \\
\text { MSAVI2 }=\frac{\left(2 * \mathrm{~B}_{8}+1-\sqrt{\left(2 * \mathrm{~B}_{8}+1\right)-8 *\left(\mathrm{~B}_{8}-\mathrm{B}_{4}\right)}\right)}{2} & \frac{\left(\mathrm{B}_{8}-\mathrm{B}_{12}\right)}{\left(\mathrm{B}_{8}+\mathrm{B}_{12}\right)}
\end{aligned}
$$

\subsubsection{Yield Estimation and Statistical Analysis}

For the comparison of VIs and VBVs deriving from S2 images with the CC canopy sensor-derived indices and their relation to the yield, a common methodology for upscaling proximal data was utilized $[37,69]$. Specifically, a grid-layer of 126 blocks of the same size was created with identical geometry and spatial resolution with the grid of satellite images (Figure 5). This grid was used as a reference layer for upscaling the values generated by proximal and yield data.

The datasets acquired from Crop Circle ACS-470 were varying in terms of density and spatial distribution. Therefore, a geostatistical spatial prediction procedure of block kriging was applied to the dataset gathered for the present study [70]. The output files of CC were imported into a GIS platform for visualizing, editing and calculating the NDVI and NDRE maps. The raster grids of the two indices were upscaled into $10 \mathrm{~m}$ pixel size to be comparable with the spatial resolution of S2-derived indices, using the mean value of the pixel situated in the same area. Subsequently, the mean values of the pixels located within each block of the reference grid were computed by the Zonal Statistics tool of the GIS platform, to represent the indices values per block.

Finally, Pearson's correlation coefficient ( $\mathrm{r}$ ) and regression analysis $\left(\mathrm{r}^{2}\right)$ were used to compare the spatial similarity between the different datasets, by measuring the strength and direction of the linear relationship among the two variables $[29,71]$.

The table grapes were harvested by hand during 16-20 August 2017. The actual yield was estimated at the harvest period by measuring the total number of bins in 50 sampling blocks and multiplying it with the average bin weight of the harvested table grapes. The sampling sites were selected randomly to represent 50 blocks of the reference grid, avoiding 
the selection of border pixels and inter-row central line, which separates the field into two parts, to reduce the influence of the soil cover.

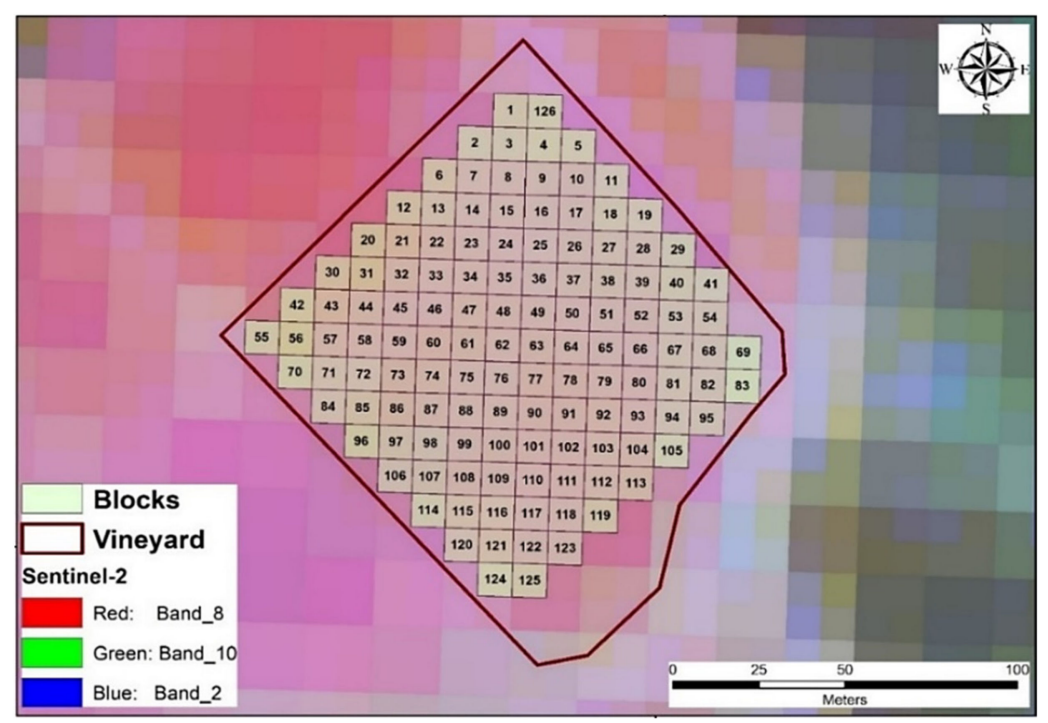

Figure 5. The study area divided into a grid of 126 blocks of the same size.

\subsubsection{Processing and Statistical Analysis Software}

The processing of the remote- and proximal-sensing data was accomplished by using ArcGIS (Environmental Systems Research Institute, Redlands, CA, USA), ENVI (Exelis Visual Information Solutions, Boulder, CO, USA), and SNAP (STEP, ESA, European Union) software.

The geostatistical analysis of the Crop Circle ACS-470 datasets was accomplished utilizing the VESPER 1.6 (Variogram Estimation and Spatial Prediction plus Error) software of the Australian Centre of Precision Agriculture [70]. The software calculates local semivariograms for each neighborhood through the local kriging process and searches for the data points within the defined site, estimating the variogram cloud by fitting a model. Thus, highly accurate maps of the spatial interpolated values are generated [54].

The statistical analysis of yield and vegetation index correlation was made by utilizing the correlation coefficient estimations and regression analysis and was performed with the statistical software Statgraphics 16 (StatPoint Technologies Inc., Warrenton, VA, USA) [72,73].

\section{Results}

\subsection{Descriptive Statistics}

Before performing the correlation analysis, basic statistics were calculated for the exploration of the data. The mean values of the proximal-based NDVI ranged from 0.60 to 0.66 , showing a reduced seasonal variability (Table 2). A bit surprisingly, Crop Circle NDVI (CCNDVI) values decreased upon the second measurement date; an explanation of that may be the farming operations during that stage (e.g., foliar fertilizers, crop grow regulators, etc.). Not surprisingly, progressive canopy growth is observed based on the descriptive statistics of four satellite-based (S) indices, namely NDVI (SNDVI), FAPAR (SFAPAR), NDRE (SNDRE), and NDWI (SNDWI), with the highest mean values occurring during the $\mathrm{H}$ crop stage. In the cases of MSAVI and FVC high mean values are also observed in the first two stages, during June. Additionally, throughout the growth stages, FVC, FAPAR, and proximal-based NDRE presented the highest degree of variation among the satellite- and proximal-based vegetation indices, with the values of coefficient of variance (CV) ranging from 10.59 to $14.59,14.56$ to 16.57 , and 1.93 to 21.39 , respectively (Table 2). Overall, FVC, FAPAR, and NDVI (proximal- and satellite-based) presented the highest mean values, while lower values, below 0.6, were observed in NDWI and NDRE. 
Table 2. Descriptive statistics of the vegetation indices (Vis) and vegetation biophysical variables (VBVs) at the five different crop stages.

\begin{tabular}{|c|c|c|c|c|c|}
\hline Sensor-VI-Growing Stage & Mean & Min & Max & SD & CV (\%) \\
\hline SV: CCNDVI/SNDVI & $0.66 / 0.61$ & $0.61 / 0.39$ & $0.71 / 0.69$ & $0.02 / 0.05$ & $3.23 / 8.31$ \\
\hline MV-1: CCNDVI/SNDVI & $0.60 / 0.62$ & $0.57 / 0.41$ & $0.63 / 0.71$ & $0.01 / 0.05$ & $2.15 / 8.67$ \\
\hline MV-2: CCNDVI/SNDVI & $0.65 / 0.63$ & $0.60 / 0.34$ & $0.67 / 0.71$ & $0.02 / 0.06$ & 2.53 \\
\hline H-1: CCNDVI/SNDVI & $0.64 / 0.67$ & $0.61 / 0.33$ & $0.67 / 0.75$ & $0.01 / 0.07$ & $1.60 / 10.75$ \\
\hline H-2: CCNDVI/SNDVI & $0.61 / 0.74$ & $0.54 / 0.41$ & $0.64 / 0.84$ & $0.02 / 0.08$ & $3.03 / 10.31$ \\
\hline SV: CCNDRE/SNDRE & $0.53 / 0.42$ & $0.50 / 0.24$ & $0.55 / 0.46$ & $0.01 / 0.03$ & $1.93 / 8.31$ \\
\hline MV-1: CCNDRE/SNDRE & $0.44 / 0.46$ & $0.22 / 0.32$ & $0.62 / 0.52$ & $0.09 / 0.04$ & $19.71 / 8.00$ \\
\hline MV-2: CCNDRE/SNDRE & $0.36 / 0.45$ & $0.32 / 0.32$ & $0.40 / 0.50$ & $0.02 / 0.04$ & $4.65 / 8.61$ \\
\hline H-1: CCNDRE/SNDRE & $0.51 / 0.48$ & $0.34 / 0.30$ & $0.63 / 0.54$ & $0.06 / 0.05$ & $11.23 / 10.81$ \\
\hline H-2: CCNDRE/SNDRE & $0.45 / 0.53$ & $0.30 / 0.25$ & $0.64 / 0.60$ & $0.10 / 0.06$ & $21.39 / 11.80$ \\
\hline SV: SMSAVI2 & 0.55 & 0.41 & 0.62 & 0.04 & 6.85 \\
\hline MV-1: SMSAVI2 & 0.53 & 0.39 & 0.59 & 0.04 & 6.60 \\
\hline MV-2: SMSAVI2 & 0.52 & 0.34 & 0.57 & 0.04 & 7.50 \\
\hline H-1: SMSAVI2 & 0.54 & 0.32 & 0.78 & 0.06 & 10.99 \\
\hline H-2: SMSAVI2 & 0.60 & 0.37 & 0.70 & 0.06 & 10.43 \\
\hline SV: SNDWI & 0.44 & 0.29 & 0.49 & 0.04 & 8.62 \\
\hline MV-1: SNDWI & 0.44 & 0.29 & 0.49 & 0.04 & 8.74 \\
\hline MV-2: SNDWI & 0.47 & 0.28 & 0.52 & 0.05 & 10.48 \\
\hline H-1: SNDWI & 0.49 & 0.25 & 0.55 & 0.06 & 11.87 \\
\hline H-2: SNDWI & 0.55 & 0.29 & 0.63 & 0.07 & 12.02 \\
\hline SV: SFVC & 0.79 & 0.41 & 0.88 & 0.08 & 10.59 \\
\hline MV-1: SFVC & 0.79 & 0.39 & 0.88 & 0.08 & 10.38 \\
\hline MV-2: S FVC & 0.75 & 0.28 & 0.83 & 0.09 & 12.12 \\
\hline H-1: S FVC & 0.77 & 0.29 & 0.87 & 0.11 & 14.59 \\
\hline H-2: S FVC & 0.85 & 0.37 & 0.94 & 0.10 & 11.89 \\
\hline SV: SFAPAR & 0.59 & 0.37 & 0.79 & 0.09 & 15.13 \\
\hline MV-1: SFAPAR & 0.61 & 0.37 & 0.80 & 0.10 & 15.78 \\
\hline MV-2: SFAPAR & 0.62 & 0.36 & 0.76 & 0.09 & 14.56 \\
\hline H-1: SFAPAR & 0.70 & 0.36 & 0.83 & 0.12 & 16.57 \\
\hline H-2: SFAPAR & 0.81 & 0.37 & 0.92 & 0.12 & 14.88 \\
\hline
\end{tabular}

CCNDVI, Crop Circle Normalized Difference Vegetation Index; SNDVI, satellite-based NDVI; CCNDRE, Crop Circle Normalized Difference Red-Edge Index; SNDRE, satellite-based NDRE; SMSAVI2, satellite-based Modified Soil Adjusted Vegetation Index 2; SNDWI, satellitebased Normalized Difference Water Index; SFVC, satellite-based Fraction of Vegetation Cover; SFAPAR, satellite-based Fraction of Absorbed Photosynthetically Active Radiation.

Moreover, according to the descriptive statistics of the measured actual yield, the values ranged from 4.5 to 19.8 tons/ha, and there seems to be a positive trend towards the eastern part of the vineyard, where it is characterized by lower production than its western part (Table 3). The mean was 16.50 tons / ha, which is considered low. The coefficient of variance $(\mathrm{CV})$ reached $18.75 \%$, which is relatively high, considering the small area of the vineyard (1.4 ha).

Table 3. Descriptive statistics of the yield measurements.

\begin{tabular}{cccccc}
\hline & Mean & Min & Max & SD & CV (\%) \\
\hline Yield & 16.50 & 4.58 & 19.82 & 3.00 & 18.75 \\
\hline
\end{tabular}

\subsection{Satellite and Proximal Based NDVI and NDRE Comparison}

The regressions of the NDVI and NDRE datasets, throughout the season, are presented in Figure 6, along with the confidence (green lines) and the prediction limits (gray lines). The output shows the plots of fitting a linear model to describe the relationship between CCNDVI and SNDVI at all growth stages. For the selection of the model, we took into 
account the table "comparison of alternative models" of Statgraphics to find the best fit. The linear regression model was selected based on the values of $R$ squared, adjusted $R$ squared, and Mean Absolute Error (MAE), since these are the most widely used evaluation metrics for the regression models (Table 4 ). The adjusted $\mathrm{r}^{2}$ of the NDVI datasets is ranging from 0.50 to 0.64 (Table 4$)$, while the lowest regression values $\left(r^{2}=0.49\right)$ were recorded on MV-2 and the best fit was reached on $\operatorname{MV}(2)\left(\mathrm{r}^{2}=0.64\right.$; Equations (5)-(9)). In the case of NDRE, the fitted models display $36 \%\left(r^{2}=0.36\right)$ and $33 \%\left(r^{2}=0.36\right)$ of the variability in proximal data at the stage of SV and H-1 (Table 4; Equations (10)-(14)). The recorded $\mathrm{r}^{2}$ between proximal and satellite NDRE datasets were below 0.30 at the other stages of the crop (MV-1, MV-2, H-1, and H-2), indicating poor prediction capability of the models.

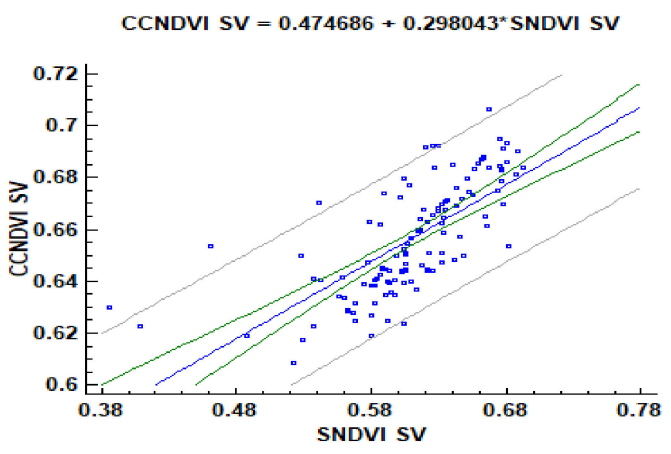

CCNDVI MV $(1)=0.481306+0.194834^{*}$ SNDVI MV(1)

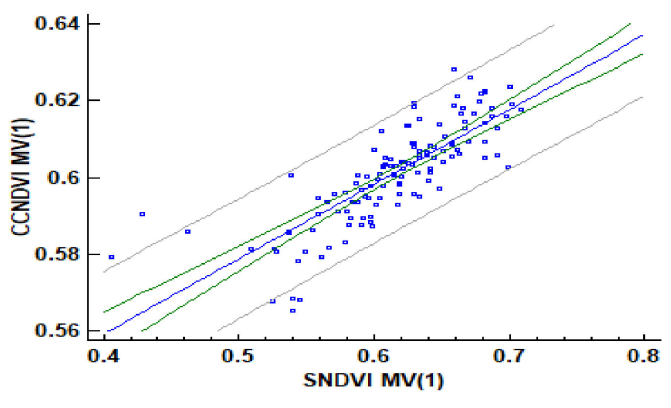

CCNDVI MV $(2)=0.524896+0.191779^{*}$ SNDVI MV $(2)$

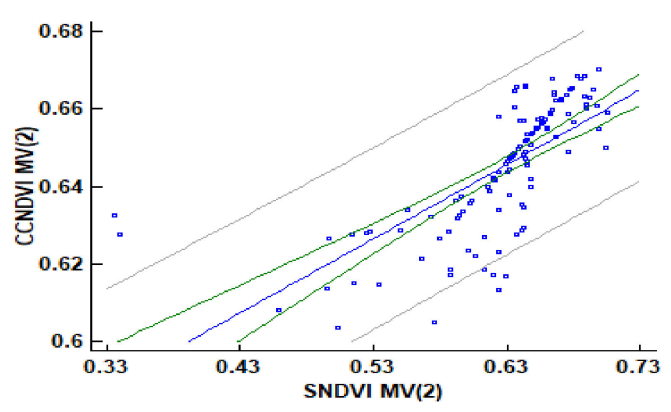

CCNDRE SV $=0.452798+0.175541^{\star}$ SNDRE SV

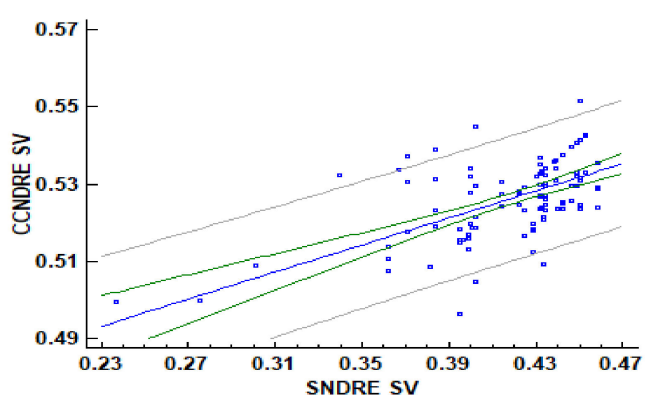

CCNDRE MV $(1)=-0.0466763+1.06139^{*}$ SNDRE MV(1)

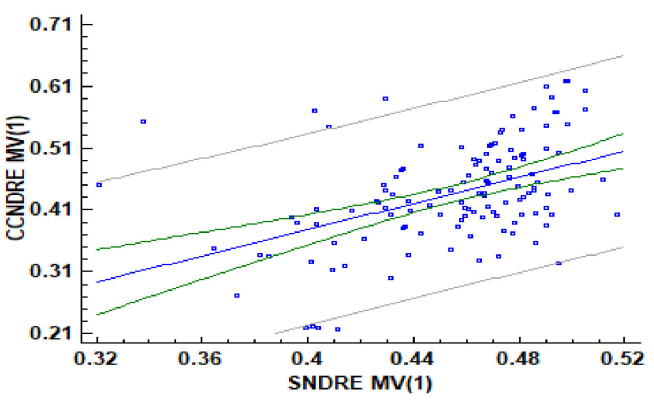

CCNDRE MV $(2)=0.252324+0.235186^{*}$ SNDRE MV(2)

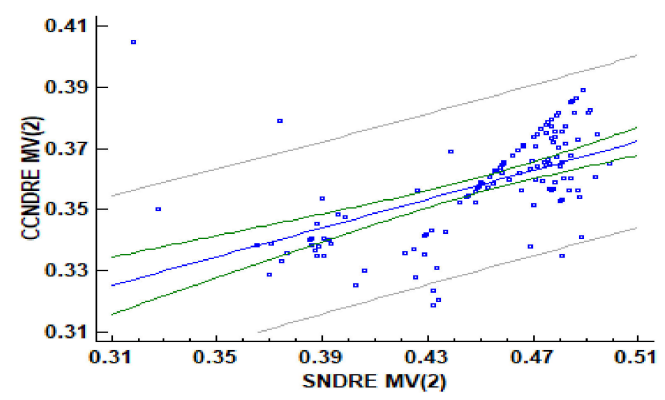

Figure 6. Cont. 

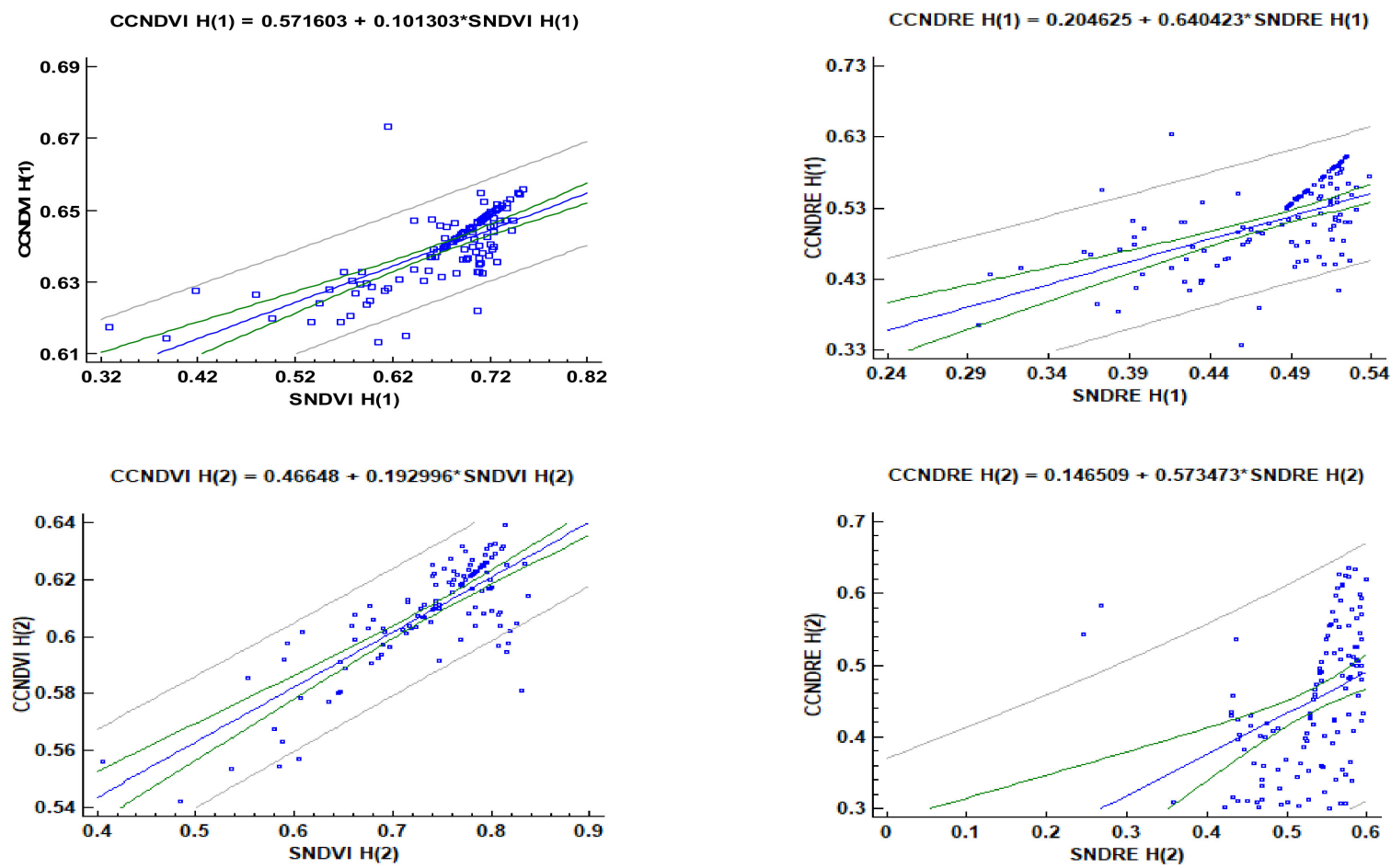

Figure 6. Regressions between NDVI and NDRE derived from Sentinel-2 images and Crop Circle sensor. Green lines show confidence, while and the gray lines show the prediction limits.

Table 4. Regression models of proximal and satellite-derived NDVI.

\begin{tabular}{|c|c|c|c|c|c|c|}
\hline \multicolumn{7}{|c|}{ Crop Circle ACS-470-NDVI } \\
\hline \multirow{6}{*}{ Sentinel-2 } & GS & $\begin{array}{c}\text { Correlation } \\
\text { Coefficient } \\
\text { Pearson-NDVI }\end{array}$ & Regression Model—NDVI & $\begin{array}{l}\text { R-Squared } \\
\text { (Adjusted for } \\
\text { d.f.) }(\%)\end{array}$ & MAE & $p$-Value \\
\hline & SV & 0.71 & $\begin{array}{l}\text { CCNDVI SV }=0.474686+ \\
0.298043 * \text { SNDVI SV }(5)\end{array}$ & 50.39 & 0.0120 & 0.00 \\
\hline & MV-1 & 0.80 & $\begin{array}{c}\text { CCNDVI MV-1 = } 0.481306+ \\
0.194834 * \text { SNDVI MV-1 }(6)\end{array}$ & 64.36 & 0.0057 & 0.00 \\
\hline & MV-2 & 0.70 & $\begin{array}{c}\text { CCNDVI MV-2 = } 0.524896+ \\
0.191779 * \text { SNDVI MV-2 (7) }\end{array}$ & 48.85 & 0.0085 & 0.00 \\
\hline & $\mathrm{H}-1$ & 0.71 & $\begin{array}{l}\text { CCNDVI H-1 = } 0.571603+ \\
0.101303 * \text { SNDVI H-1 (8) }\end{array}$ & 51.09 & 0.0051 & 0.00 \\
\hline & H-2 & 0.79 & $\begin{array}{c}\text { CCNDVI H(2) }=0.46648+ \\
0.192996^{*} \text { SNDVI H-2 (9) }\end{array}$ & 63.27 & 0.0085 & 0.00 \\
\hline
\end{tabular}


Table 4. Cont.

\begin{tabular}{|c|c|c|c|c|c|c|}
\hline \multicolumn{7}{|c|}{ Crop Circle ACS-470-NDRE } \\
\hline \multirow{6}{*}{ Sentinel-2 } & GS & $\begin{array}{c}\text { Correlation } \\
\text { Coefficient } \\
\text { Pearson-NDRE }\end{array}$ & Regression Model-NDRE & $\begin{array}{l}\text { R-Squared } \\
\text { (Adjusted for } \\
\text { d.f.) }\end{array}$ & MAE & $p$-Value \\
\hline & SV & 0.60 & $\begin{array}{l}\text { CCNDRE SV }=0.452798+ \\
0.175541 * \text { SNDRE SV }(10)\end{array}$ & 35.50 & 0.0064 & 0.00 \\
\hline & MV-1 & 0.45 & $\begin{array}{l}\text { CCNDRE MV- } 1=-0.0466763 \\
+1.06139 * \text { SNDRE MV-1 }(11)\end{array}$ & 19.58 & 0.0597 & 0.00 \\
\hline & MV-2 & 0.55 & $\begin{array}{l}\text { CCNDRE MV-2 = } 0.252324+ \\
0.235186 * \text { SNDRE MV-2 }(12)\end{array}$ & 29.35 & 0.0096 & 0.00 \\
\hline & $\mathrm{H}-1$ & 0.58 & $\begin{array}{l}\text { CCNDRE H-1 }=0.204625+ \\
0.640423 * \text { SNDRE H-1 (13) }\end{array}$ & 32.70 & 0.0370 & 0.00 \\
\hline & $\mathrm{H}-2$ & 0.37 & $\begin{array}{l}\text { CCNDRE H-2 = } 0.146509+ \\
0.573473 * \text { SNDRE H-2 }(14)\end{array}$ & 13.16 & 0.0719 & 0.00 \\
\hline
\end{tabular}

GS, growth stage.

The NDVI and NDRE maps were created and classified into three classes (low, medium, and high), using the quantile classing method to demonstrate the spatial distribution of the VIs' values (Figure 7). Following previous studies [56], the quantile classification method was used only for visual interpretation of VIs and yield. The method was not used to define management zones. There are many classification methods for visualization available, including quantiles, natural breaks, equal intervals, and standard deviations $[74,75]$. According to ArcGIS help, which provides a detailed description of this schema, the quantile classification is well suited to linearly distributed data, grouping features in equal numbers in each class. To this end, three classes were considered sufficient. Note that if the data distribution has a positive or negative skewness, the quantile or natural break distribution classifiers could be chosen [76]. In the current study, and by considering the distribution histograms of the datasets, the "quantile classifier" was chosen and applied as the most suitable for the visualization of our dataset.

The exploratory analysis of the data revealed considerable spatial variation, and the thematic maps presented some spatial patterns with a trend of higher values occurring at the center and western part of the field, especially in the case of S2 data.

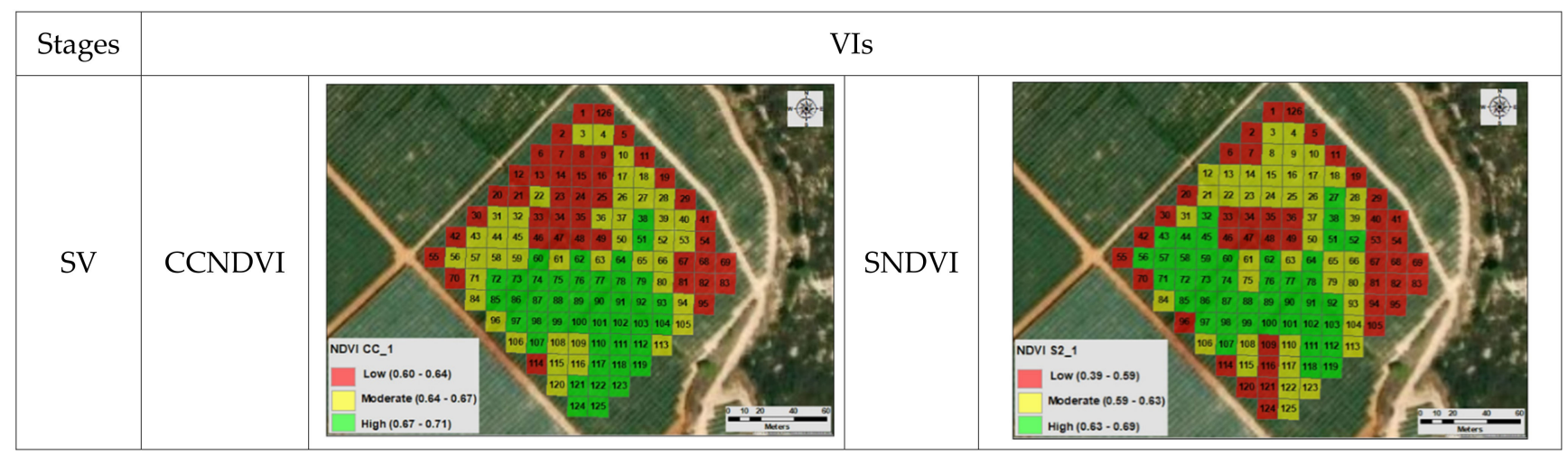

Figure 7. Cont. 


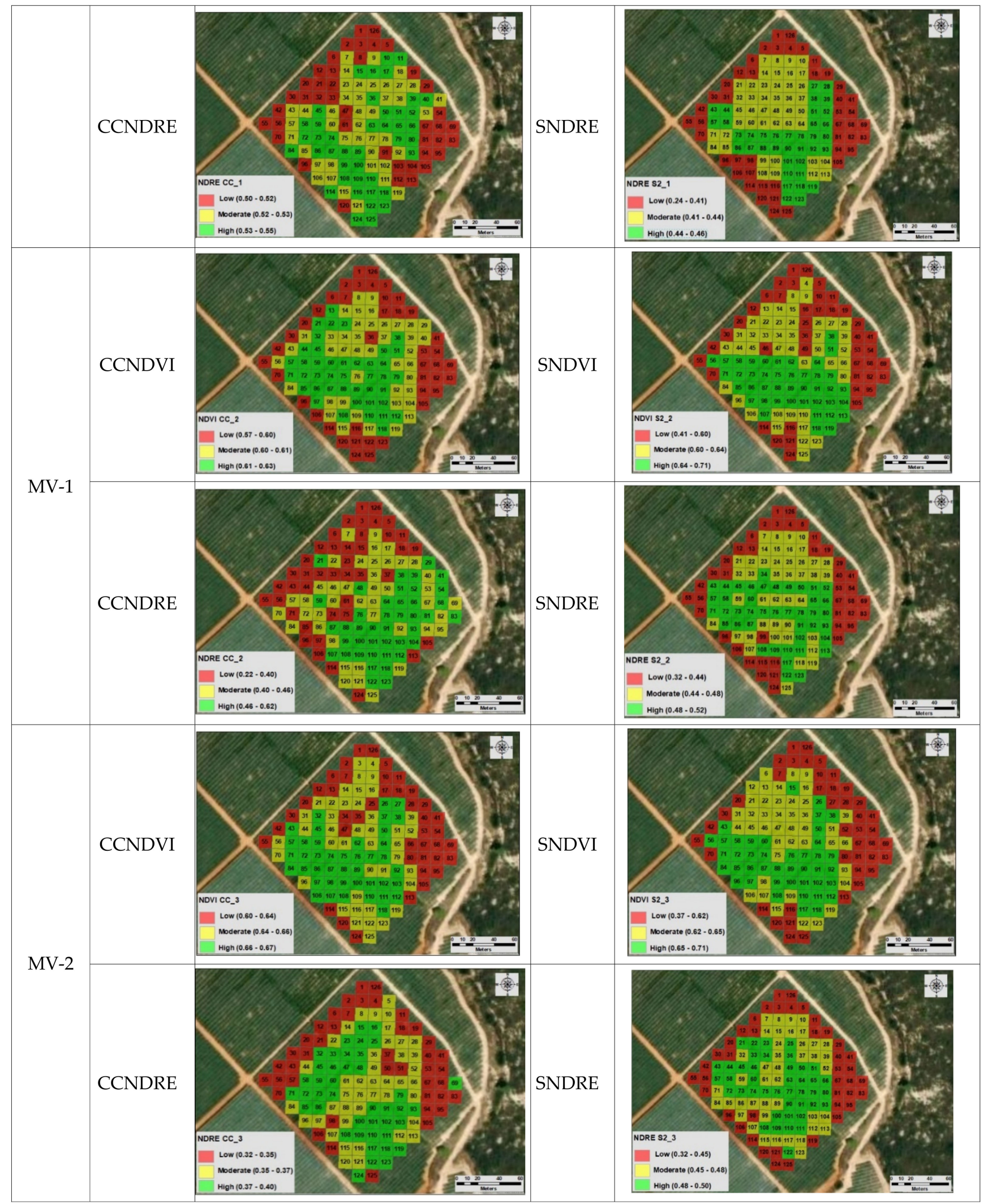

Figure 7. Cont. 


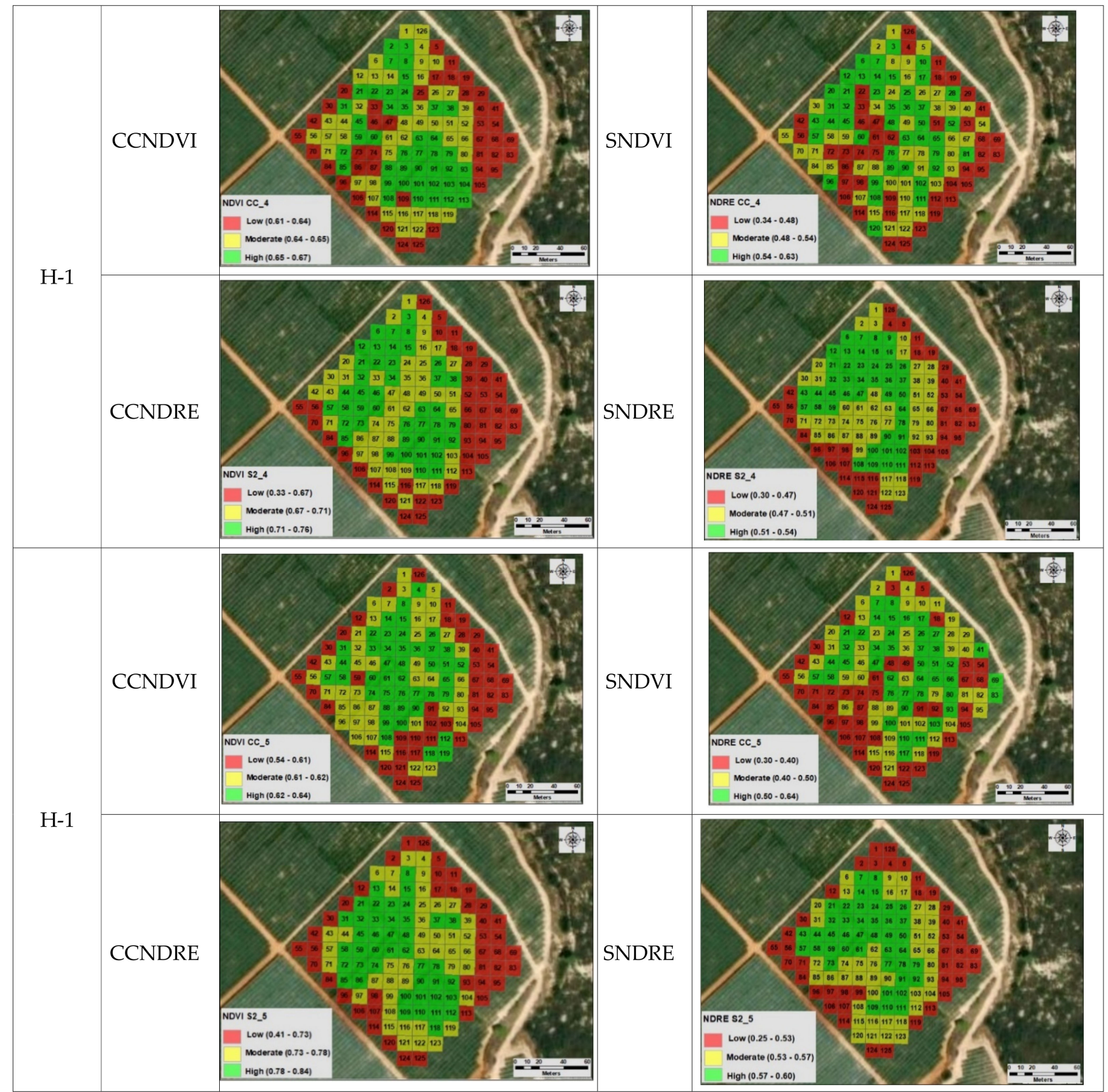

Figure 7. NDVI and NDRE maps showing the indices values spatial variation, derived from satellite (Sentinel-2 (S2)) and proximal (Crop Circle (CC)) datasets for the five different stages.

\subsection{Vegetation Indices and Yield Measurements}

The VIs and VBVs maps were also created and classified into three classes (low, medium, and high), using the quantile classing method to demonstrate the spatial distribution of their values (Figure 8). The same classification was also made for the yield spatial distribution (Figure 9).

Thereinafter the correlation analysis of both VIs and VBVs values, from the proximal and remote sensors, at all the selected growth stages with the yield measurements, were conducted. The results display that the CCNDVI and CCNDRE have a lower correlation than SNDVI and SNDRE, respectively (Table 5). The correlation of CCNDRE was, unexpectedly, extremely low, much lower than the SNDRE, and, in general, the CC values were lower than the satellite (S2) values. The stage of MV-2 appears to be the most suitable date 
for proximal and satellite measurements (NDVI and NDRE), due to the higher correlation values ( 0.87 and 0.78 for $\mathrm{S}$, and 0.76 and 0.59 for $\mathrm{CC}$, respectively).

As far as it concerns the correlation of both VIs and VBVs values that derived from S2 data, the maximum positive correlation with the yield was observed from NDVI and FAPAR, mainly at the MV-2 growth stage (0.87) and a suitable positive correlation at the SV and MV-1 stages, varying from 0.74 to 0.78 (Figure 10). The maximum correlation values of the NDRE occurred also at the MV-2 stage (0.78) and the minimum primarily at the $\mathrm{H}-1$ stage and less at the $\mathrm{H}-2$ stages, 0.60 and 0.67 respectively. (Figure 9).

On the other hand, the other three indices MSAVI2, NDWI, and FVC demonstrate a very low correlation at all stages, and only at the MV-2 stage do they demonstrate a quite acceptable value (Figure 9). In particular, the NDWI and (less so) the FVC display very low correlation values mainly at the first two stages, SV and MV-1, varying from 0.37 to 0.54.

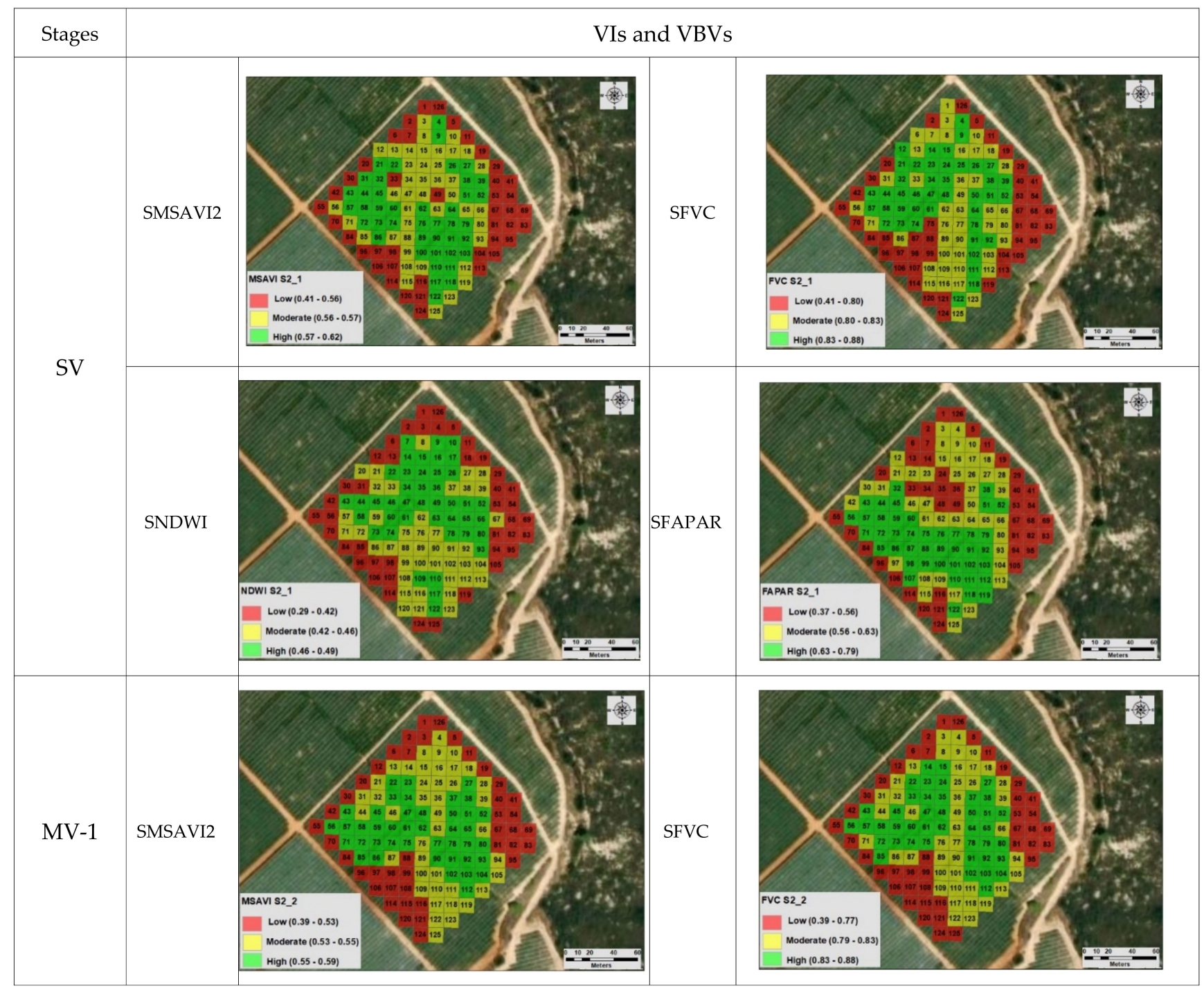

Figure 8. Cont. 


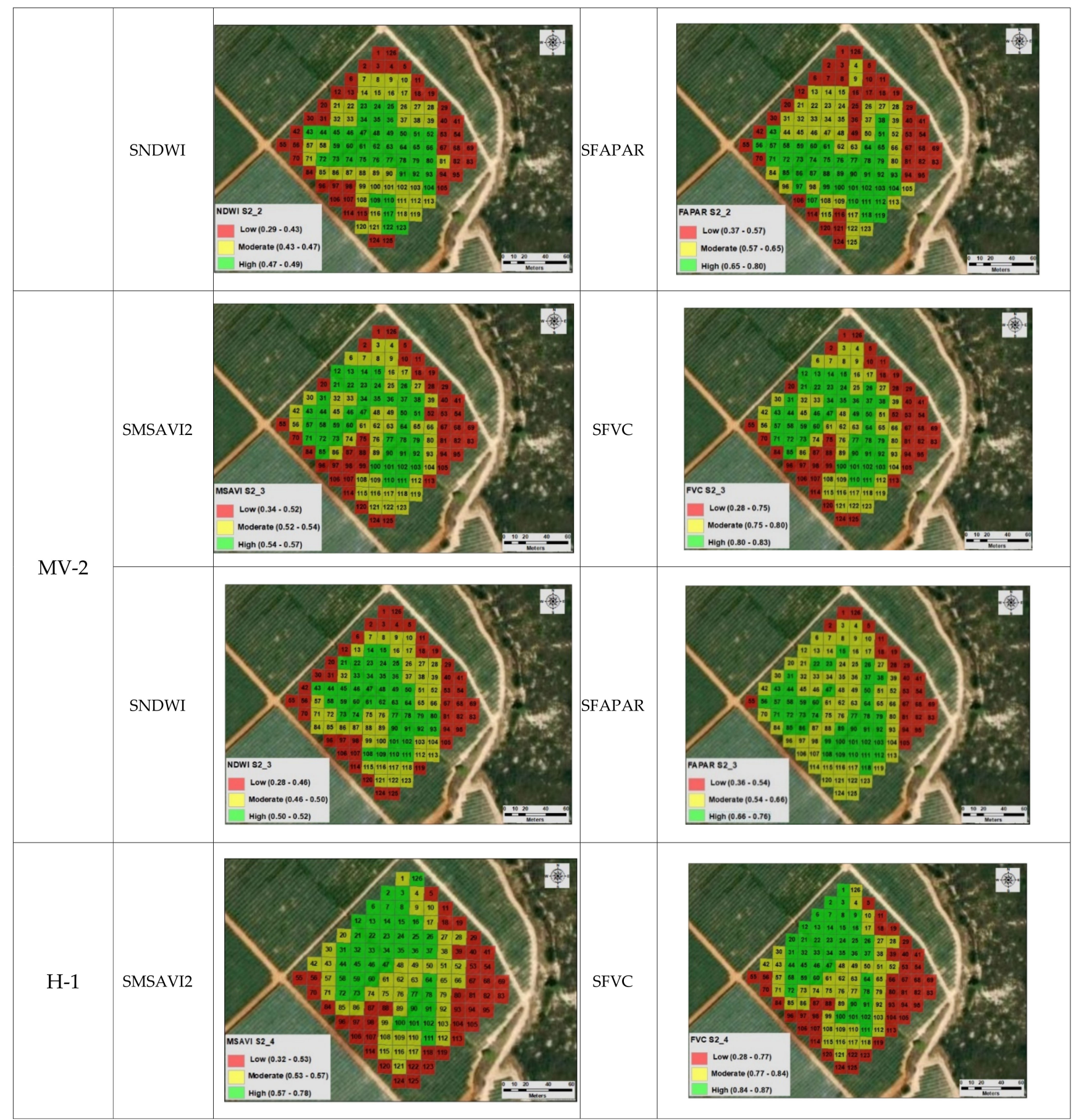

Figure 8. Cont. 




Figure 8. MSAVI2, NDWI, FVC, and FAPAR maps showing the indices values spatial variation, derived from satellite dataset for the five different stages.

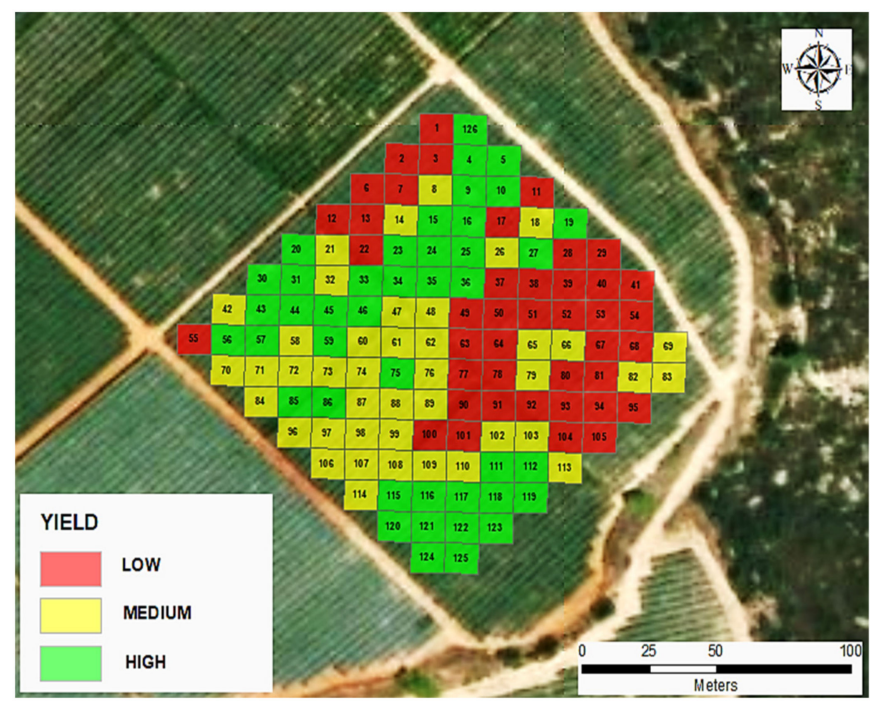

Figure 9. Yield map showing the spatial distribution of the grape production classified into three classes (low, medium, and high). 
Table 5. Coefficients of determination $\left(\mathrm{r}^{2}\right)$ of the linear relationships of CCNDVI and SNDVI values with yield.

\begin{tabular}{ccccc}
\hline \multirow{2}{*}{ Growth Stages } & \multicolumn{3}{c}{ Yield } \\
\cline { 2 - 5 } & CCNDVI & SNDVI & CCNDRE & SNDRE \\
\cline { 2 - 5 } & \multicolumn{3}{c}{ Pearson } \\
\hline SV & 0.59 & 0.74 & 0.39 & 0.70 \\
MV-1 & 0.59 & 0.76 & 0.23 & 0.60 \\
MV-2 & 0.76 & 0.87 & 0.59 & 0.78 \\
H-1 & 0.50 & 0.65 & 0.30 & 0.60 \\
H-2 & 0.59 & 0.68 & 0.30 & 0.67 \\
\hline
\end{tabular}

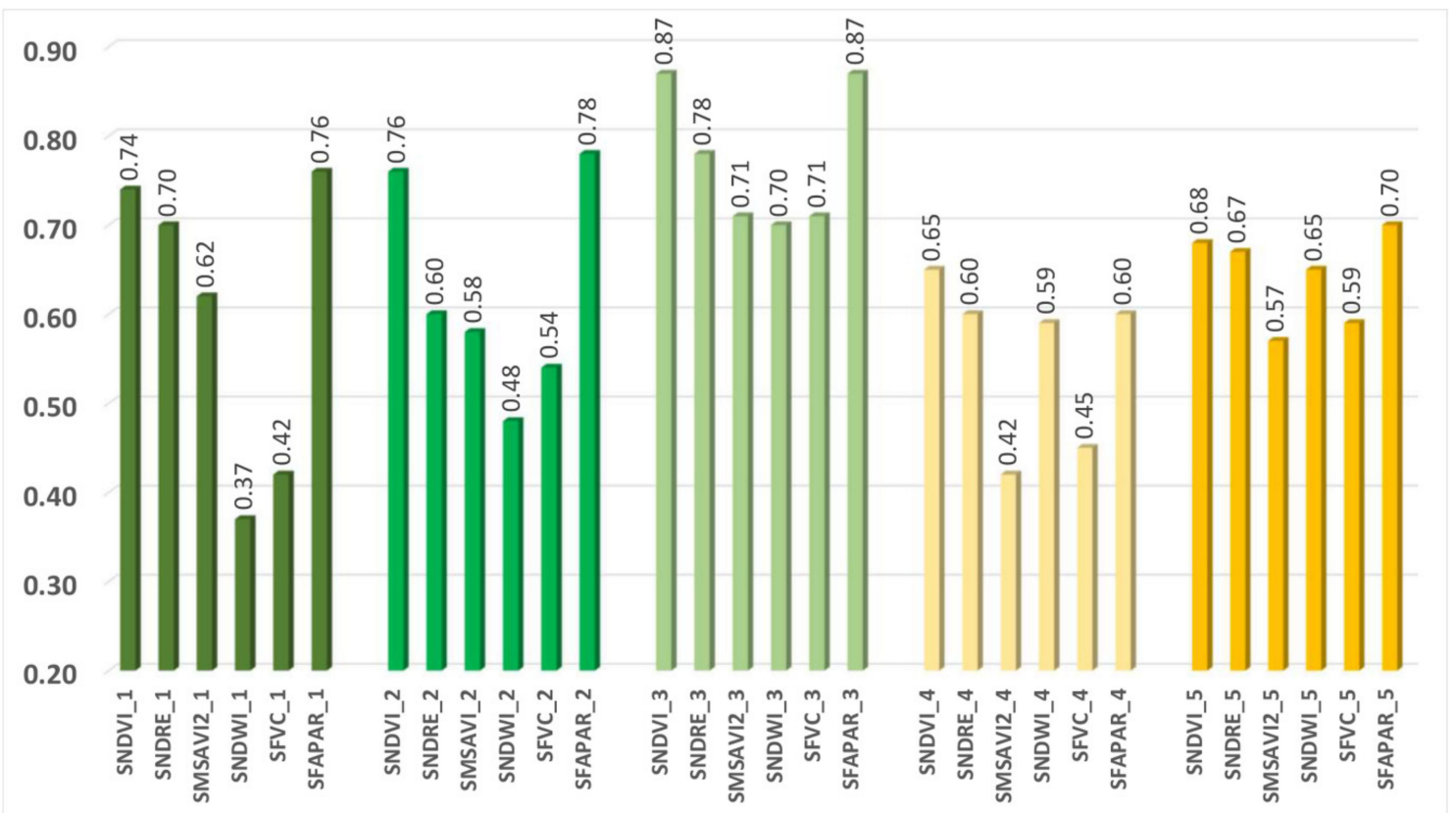

Figure 10. The Coefficients of determination representing the correlation of the S2-derived VIs and VBVs values with the yield.

\section{Discussion}

\subsection{Proximal- and Remote-Sensing Multi-Seasonal Comparison}

The use of multi-seasonal remote- and proximal-sensing sensors, which provide specific multispectral data, demonstrates to be an ideal tool to map the vineyard conditions, monitor their development through their growth stages, and assist in the estimation of the production from an early phase of crop growth. Several research studies have been developed, especially during the last few decades, dealing with the implementation of remote and proximal sensors in viticulture, such as those of Sozzi et al. [57], Gatti et al. [77], and Matese et al. [37], which used VIs derived from S2 and UAV sensors for vineyard monitoring. Bramley et al. [32], Taskos et al. [33], Anastasiou et al. [29], Reynolds et al. [78], Primicerio et al. [79], Magarreiro et al. [45], Borgogno-Mondino et al. [46], and Stamatiadis et al. [31] utilized VIs or VBVs obtained from Crop Circle and remotely sensed imagery for assessing vineyard's conditions and their relation to yield variability. Henry et al. [80], Arnó et al. [6], and Stamatiadis et al. [81] used several different proximal sensors, along with GPS and VRA to evaluate the characteristics of vineyards, while other scientists, such as Meggio et al. [19], Xue and Su [42], and Martínez-Beltrán et al. [82], utilized for the same reason various remote sensors (hyperspectral or thermal). 
Multi-seasonal measurements during several different growth stages, like the selected in the present study, appear to be a reliable source of information to draw reliable conclusions about the development of the crop, as it is also examined and highlighted by several other previous studies, such as those of Anastasiou et al. [5,38], Kazmierski et al. [56], Lamb et al. [18], Taskos et al. [33], and Mathews [83]. The correlation analysis for each stage of development separately aimed to distinguish the most important period for the development of the crop and its correlation with production.

For this study, the extensively tested and analyzed broadband vegetation index, NDVI and the narrowband index, NDRE, were selected for the comparison of satellite and proximal-derived datasets [24,37,46,77,82,84-87]. Based on the results, significant correlations were recorded mainly for the NDVI, where the statistical analysis indicated the robust relationships between the proximal and remote-sensing NDVI datasets, displaying satisfactory linear correlation coefficient results, especially for the period of veraison (MV2 ) and harvest $(\mathrm{H})$. These results indicate that the top canopy's vine leaves had higher photosynthetic rates at these stages and provide new insights into the monitoring of vineyards at a medium resolution scale. The fact that the differences between the minimum and maximum values of the VIs derived from the CC were very small probably due to the very high proximity of the CC scanner and the canopy, which affect insignificant the comparison and the relation of the indices. On the other hand, surprisingly, for the NDRE, the correlation was not accordingly suitable. In the case of NDRE, the low correlation with the yield is probably related to the fact that the red-edge band is associated with the visualization of chlorophyll content in leaves that, during the selected growth stages, has reached its maximum values and displays a significant decrease thereafter. Moreover, the narrowband greenness VIs, such as NDRE, are combinations of reflectance measurements sensitive to the combined effects of foliage chlorophyll concentration, canopy leaf area, foliage clumping, and canopy architecture. Thus, it is apparent from the results that these parameters in our case in the specific vineyard field are not ideal to reach a satisfactory correlation [88].

\subsection{VIs-VBVs and Yield Correlation}

As far as it concerns the relationship of the VIs and VBVs with the yield, the highest correlations were detected by NDVI and FAPAR vegetation indicators. Although the NDVI has been commonly used to focus on vineyards' conditions and, consequently, wine production $[38,89]$, the disposal of FAPAR estimates from satellite data releases the possibility to evaluate the state of the vineyard health and production through a variable closer to photosynthesis processes.

On the other hand, NDRE provided quite acceptable results, while MSAVI2, NDWI, and FVC delivered inadequate and ineffective outcomes. MSAVI was tested because NDVI is sensitive to the effects of soil brightness and leaf-canopy shade that, in some cases, necessitate targeted processing and calibration [42]. Therefore, several types of research have mentioned that utilizing medium-resolution satellites to assess vineyard characteristics is risky due to their large heterogeneity and narrow line spacing, and, consequently, only a few studies have been conducted in the field of viticulture with such satellite systems [29,90]. In our experimental field, we have concluded that the gaps between the lines were too small, concerning the spatial resolution of S2 data, to achieve differences in the results by implementing MSAVI2 instead of NDVI, which is more accurate when inter-row soil lines are wide. Moreover, it was ineffective for the same reason as the attempt to separate these lines from the S2 images [57]. On the other hand, the lines were too large for trying to make the scanning of CC from a higher altitude to simulate the acquisition with the perspective view of the satellite sensor. Nevertheless, in the case of PS, a significant reduction of soil reflectance interference was noted considering that the sensor scanning takes place in close proximity to the vine canopy [81]. Additionally, the low correlation values of NDWI are probably related to the lack of irrigation and the low or 
zero rainfall values during the summer that create extremely dry conditions at the canopy. Their utilization could be more reliable for irrigated crops.

The low correlation values of all indices at the $\mathrm{H}-1$ stage, especially of those derived from the CC sensor, probably may be explained partly by the fact that table grapes received numerous crop practices on the canopy, like the defoliation procedure intended for the grape ripening, which caused a restructuring effect on the canopy characteristics and consequently to the measurements occurred there. Likewise, the correlation between the vegetation index and vineyard yield was higher when the border pixels were removed from the calculation procedure in the case of S2 data, due to the edge effects of the vineyard surrounding area on the spectral response. However, this process is extremely risky, especially at small fields, where the border pixels comprise a large part of the vineyard [57]. This limitation will be eliminated in the following years with the expansion of the very high spatial resolutions satellites and UAVs [2,91].

Furthermore, the highest correlations were found at the same crop stage for each of the proximal and remote methods, during the middle of veraison (MV-2). This outcome agrees with the findings of Anastasiou et al. [29] and Garcia-Estevez et al. [92] which found also the highest correlation during the same growth stage (MV-2). Moreover, the highest correlation of S2-values in comparison to the CC-values, during all growth stages and especially in veraison, is probably related to the physiology of the vines. In particular, the vine's mature leaves are developed near the trunk at the initiation of vine growth, but as the vine grows to senescence, these leaves are found at the edge of the shoot. Consequently, the leaves that are at the side canopy, which are measured with proximal sensing, thus providing lower values in comparison with the $\mathrm{S} 2$ that measures the photosynthetic activity of the top canopy leaves.

The fact that the higher correlation was identified at the northwestern and western part of the vineyard almost certainly is related to the geomorphological and soil characteristics, since the experimental field is characterized by a slight slope that extends to the central part of the plot from north to south, and better soil properties at the western part that might affect production and vine conditions.

\section{Conclusions}

In this study, an assessment of different sensing methods (satellite and proximal) for monitoring crop conditions through several VIs and VBVs, and their relation to the yield, was conducted, during 2017, on a commercial table grape vineyard. The vegetation indicators were calculated based on the spectral information that was derived from Sentinel2 and Crop Circle. The results demonstrated the potential of S2 images and CC data to characterize vineyard blocks' vigor and to monitor winegrowers' practices at a territorial (regional) scale.

The results were encouraging in the view of developing a wide-scale monitoring system, especially relying on the Sentinel-2 mission, allowing free access to data with high spatial and temporal resolution from most regions of the world. The conclusions from this study will be also beneficial for improving the applications of Crop Circle in production fields. Moreover, the fact that CC is independent of an external light-source existence, it is not affected by ambient conditions (weather, cloud cover, etc.) makes it a valuable tool for precise viticulture monitoring in any condition, day, or night.

The findings of proximal- and remote-sensing analysis reveal a satisfactory correlation of VIs and VBVs with the yield at specific vine growth stages (MV-2). Agronomists and farmers having this valuable knowledge as a pilot tool can implement precise spatial distributed intervention practices to improve the condition of the plants increasing, and hence, the production.

In general, the results of the present study are encouraging and give the impetus for further research over a longer period, a larger number of experimental plots, and by considering more parameters and/or vegetation indices from comparable sensors. Moreover, an added value of this work is that it presents a perspective for vineyard 
production estimation using data that are easily accessible, free, and available for numerous grapevines regions in alternative to continuous in situ measurements, which commonly are difficult to access and often associated with extra costs.

Our research attempted to create an operational tool, trying to relate the vineyard vegetation conditions with the yield, using different sensors, in various growth stages, in order to be used as a guide for the production estimation on a broader scale (regional or national). The achievement of such an effort necessitates further research and field measurements to accomplish a trustworthy methodology.

Author Contributions: Conceptualization, N.D., E.P., A.K., A.A. and S.F.; fieldwork, N.D., A.K., E.A. and S.F.; methodology, N.D., E.P. and S.F.; processing, N.D., A.K. and S.F.; statistical analysis, N.D., E.A. and A.A.; validation, N.D., E.P., A.K., A.A. and S.F.; formal analysis, N.D., E.P., A.K., E.A., A.A. and S.F.; writing - original draft preparation, N.D., E.P., E.A. and S.F.; writing-review and editing, N.D., E.P., E.A. and S.F.; supervision, E.P., E.A. and S.F. All authors have read and agreed to the published version of the manuscript.

Funding: This research received no external funding.

Institutional Review Board Statement: Not applicable.

Informed Consent Statement: Not applicable.

Data Availability Statement: Data sharing is not applicable to this article.

Acknowledgments: We would like to acknowledge the European Space Agency for the availability of Sentinel data. We would also like to thank Dimitris Theodorou and Pegasus COOP for their collaboration in conducting our field experiments in their field.

Conflicts of Interest: The authors declare no conflict of interest.

\section{References}

1. Cunha, M.; Marçal, A.R.S.; Silva, L. Very early prediction of wine yield based on satellite data from Vegetation. Int. J. Remote Sens. 2010, 31, 3125-3142. [CrossRef]

2. Matese, A.; Di Gennaro, S.F. Technology in precision viticulture: A state of the art review. Int. J. Wine Res. 2015, 7, 69. [CrossRef]

3. Hall, A.; Lamb, D.W.; Holzapfel, B.; Louis, J. Optical remote sensing applications in viticulture-A review. Aust. J. Grape Wine Res. 2002, 8, 36-47. [CrossRef]

4. Belmonte, A.C.; Jochum, A.M.; García, A.C.; Rodríguez, A.M.; Fuster, P.L. Irrigation management from space: Towards userfriendly products. Irrig. Drain. Syst. 2005, 19, 337-353. [CrossRef]

5. Anastasiou, E.; Tsiropoulos, Z.; Balafoutis, T.; Fountas, S.; Templalexis, C.; Lentzou, D.; Xanthopoulos, G. Spatiotemporal stability of management zones in a table grapes vineyard in Greece. Adv. Anim. Biosci. 2017, 8, 510-514. [CrossRef]

6. Arnó, J.; Martínez-Casasnovas, J.A.; Ribes-Dasi, M.; Rosell, J.R. Review. Precision Viticulture. Research topics, challenges and opportunities in site-specific vineyard management. Span. J. Agric. Res. 2009, 7, 779-790. [CrossRef]

7. Campos, I.; González-Gómez, L.; Villodre, J.; Calera, M.; Campoy, J.; Jiménez, N.; Plaza, C.; Sánchez-Prieto, S.; Calera, A. Mapping within-field variability in wheat yield and biomass using remote sensing vegetation indices. Precis. Agric. 2019, 20, 214-236. [CrossRef]

8. Pallottino, F.; Biocca, M.; Nardi, P.; Figorilli, S.; Menesatti, P.; Costa, C. Science mapping approach to analyze the research evolution on precision agriculture: World, EU and Italian situation. Precis. Agric. 2018, 19, 1011-1026. [CrossRef]

9. Khaliq, A.; Comba, L.; Biglia, A.; Ricauda Aimonino, D.; Chiaberge, M.; Gay, P. Comparison of Satellite and UAV-Based Multispectral Imagery for Vineyard Variability Assessment. Remote Sens. 2019, 11, 436. [CrossRef]

10. Di Gennaro, S.F.; Matese, A.; Gioli, B.; Toscano, P.; Zaldei, A.; Palliotti, A.; Genesio, L. Multisensor approach to assess vineyard thermal dynamics combining high-resolution unmanned aerial vehicle (UAV) remote sensing and wireless sensor network (WSN) proximal sensing. Sci. Hortic. (Amst.) 2017, 221, 83-87. [CrossRef]

11. Kavvadias, A.; Psomiadis, E.; Chanioti, M.; Tsitouras, A.; Toulios, L.; Dercas, N. Unmanned Aerial Vehicle (UAV) data analysis for fertilization dose assessment. In Proceedings of the SPIE-The International Society for Optical Engineering, Warsaw, Poland, 2 November 2017; Volume 10421.

12. Hall, A.; Wilson, M.A. Object-based analysis of grapevine canopy relationships with winegrape composition and yield in two contrasting vineyards using multitemporal high spatial resolution optical remote sensing. Int. J. Remote Sens. 2013, 34, $1772-1797$. [CrossRef] 
13. Psomiadis, E.; Dercas, N.; Dalezios, N.R.; Spiropoulos, N. Evaluation and cross-comparison of vegetation indices for crop monitoring from sentinel-2 and worldview-2 images. In Proceedings of the Remote Sensing for Agriculture, Ecosystems, and Hydrology XIX, Warsaw, Poland, 12-14 September 2017; Neale, C.M., Maltese, A., Eds.; SPIE-International Society for Optics and Photonics: Warsaw, Poland, 2017; Volume 10421, p. 79.

14. Fountas, S.; Espejo-Garcia, B.; Kasimati, A.; Mylonas, N.; Darra, N. The Future of Digital Agriculture: Technologies and Opportunities. IT Prof. 2020, 22, 24-28. [CrossRef]

15. Fountas, S.; Aggelopoulou, K.; Bouloulis, C.; Nanos, G.D.; Wulfsohn, D.; Gemtos, T.A.; Paraskevopoulos, A.; Galanis, M. Site-specific management in an olive tree plantation. Precis. Agric. 2011, 12, 179-195. [CrossRef]

16. De Benedetto, D.; Castrignano, A.; Diacono, M.; Rinaldi, M.; Ruggieri, S.; Tamborrino, R. Field partition by proximal and remote sensing data fusion. Biosyst. Eng. 2013, 114, 372-383. [CrossRef]

17. Mulla, D.J. Twenty five years of remote sensing in precision agriculture: Key advances and remaining knowledge gaps. Biosyst. Eng. 2013, 114, 358-371. [CrossRef]

18. Lamb, D.W.; Weedon, M.M.; Bramley, R.G.V. Using remote sensing to predict grape phenolics and colour at harvest in a Cabernet Sauvignon vineyard: Timing observations against vine phenology and optimising image resolution. Aust. J. Grape Wine Res. 2008, 10, 46-54. [CrossRef]

19. Meggio, F.; Zarco-Tejada, P.J.; Núñez, L.C.; Sepulcre-Cantó, G.; González, M.R.; Martín, P. Grape quality assessment in vineyards affected by iron deficiency chlorosis using narrow-band physiological remote sensing indices. Remote Sens. Environ. 2010, 114, 1968-1986. [CrossRef]

20. Mouazen, A.M.; Alexandridis, T.; Buddenbaum, H.; Cohen, Y.; Moshou, D.; Mulla, D.; Nawar, S.; Sudduth, K.A. Monitoring. In Agricultural Internet of Things and Decision Support for Precision Smart Farming; Elsevier Inc.: Amsterdam, The Netherlands, 2020; pp. 35-138, ISBN 9780128183731.

21. Chatziantoniou, A.; Petropoulos, G.P.; Psomiadis, E. Co-Orbital Sentinel 1 and 2 for LULC mapping with emphasis on wetlands in a mediterranean setting based on machine learning. Remote Sens. 2017, 9, 1259. [CrossRef]

22. Psomiadis, E.; Soulis, K.X.; Efthimiou, N. Using SCS-CN and earth observation for the comparative assessment of the hydrological effect of gradual and abrupt spatiotemporal land cover changes. Water 2020, 12, 1386. [CrossRef]

23. Belgiu, M.; Csillik, O. Sentinel-2 cropland mapping using pixel-based and object-based time-weighted dynamic time warping analysis. Remote Sens. Environ. 2018, 204, 509-523. [CrossRef]

24. Di Gennaro, S.; Dainelli, R.; Palliotti, A.; Toscano, P.; Matese, A. Sentinel-2 Validation for Spatial Variability Assessment in Overhead Trellis System Viticulture Versus UAV and Agronomic Data. Remote Sens. 2019, 11, 2573. [CrossRef]

25. Esch, T.; Metz, A.; Marconcini, M.; Keil, M. Combined use of multi-seasonal high and medium resolution satellite imagery for parcel-related mapping of cropland and grassland. Int. J. Appl. Earth Obs. Geoinf. 2014, 28, 230-237. [CrossRef]

26. Löw, F.; Michel, U.; Dech, S.; Conrad, C. Impact of feature selection on the accuracy and spatial uncertainty of per-field crop classification using Support Vector Machines. ISPRS J. Photogramm. Remote Sens. 2013, 85, 102-119. [CrossRef]

27. Fountas, S.; Anastasiou, E.; Balafoutis, A.; Koundouras, S.; Theoharis, S.; Theodorou, N. The influence of vine variety and vineyard management on the effectiveness of canopy sensors to predict winegrape yield and quality. In Proceedings of the International Conference of Agricultural Engineering, Zurich, Switzerland, 6-10 July 2014; p. 8.

28. Lamb, D.W.; Trotter, M.G.; Schneider, D.A. Ultra low-level airborne (ULLA) sensing of crop canopy reflectance: A case study using a CropCircle ${ }^{\mathrm{TM}}$ sensor. Comput. Electron. Agric. 2009, 69, 86-91. [CrossRef]

29. Anastasiou, E.; Castrignanò, A.; Arvanitis, K.; Fountas, S. A multi-source data fusion approach to assess spatial-temporal variability and delineate homogeneous zones: A use case in a table grape vineyard in Greece. Sci. Total Environ. 2019, 684, 155-163. [CrossRef] [PubMed]

30. Cao, Q.; Miao, Y.; Feng, G.; Gao, X.; Li, F.; Liu, B.; Yue, S.; Cheng, S.; Ustin, S.L.; Khosla, R. Active canopy sensing of winter wheat nitrogen status: An evaluation of two sensor systems. Comput. Electron. Agric. 2015, 112, 54-67. [CrossRef]

31. Stamatiadis, S.; Taskos, D.; Tsadila, E.; Christofides, C.; Tsadilas, C.; Schepers, J.S. Comparison of passive and active canopy sensors for the estimation of vine biomass production. Precis. Agric. 2010, 11, 306-315. [CrossRef]

32. Bramley, R.G.V.; Trought, M.C.T.; Praat, J.-P. Vineyard variability in Marlborough, New Zealand: Characterising variation in vineyard performance and options for the implementation of Precision Viticulture. Aust. J. Grape Wine Res. 2011, 17, 72-78. [CrossRef]

33. Taskos, D.G.; Koundouras, S.; Stamatiadis, S.; Zioziou, E.; Nikolaou, N.; Karakioulakis, K.; Theodorou, N. Using active canopy sensors and chlorophyll meters to estimate grapevine nitrogen status and productivity. Precis. Agric. 2014, 16, 77-98. [CrossRef]

34. Yao, Y.; Miao, Y.; Jiang, R.; Khosla, R.; Gnyp, M.L.; Bareth, G. Evaluating different active crop canopy sensors for estimating rice yield potential. In Proceedings of the 2013 2nd International Conference on Agro-Geoinformatics: Information for Sustainable Agriculture, Agro-Geoinformatics 2013, Fairfax, VI, USA, 12-16 August 2013; pp. 538-542.

35. Li, F.; Miao, Y.; Feng, G.; Yuan, F.; Yue, S.; Gao, X.; Liu, Y.; Liu, B.; Ustin, S.L.; Chen, X. Improving estimation of summer maize nitrogen status with red edge-based spectral vegetation indices. Field Crop. Res. 2014, 157, 111-123. [CrossRef]

36. Cao, Q.; Miao, Y.; Li, F.; Gao, X.; Liu, B.; Lu, D.; Chen, X. Developing a new Crop Circle active canopy sensor-based precision nitrogen management strategy for winter wheat in North China Plain. Precis. Agric. 2017, 18, 2-18. [CrossRef] 
37. Matese, A.; Di Gennaro, S.F.; Miranda, C.; Berton, A.; Santesteban, L.G. Evaluation of spectral-based and canopy-based vegetation indices from UAV and Sentinel 2 images to assess spatial variability and ground vine parameters. Adv. Anim. Biosci. 2017, 8, 817-822. [CrossRef]

38. Anastasiou, E.; Balafoutis, A.; Darra, N.; Psiroukis, V.; Biniari, A.; Xanthopoulos, G.; Fountas, S. Satellite and Proximal Sensing to Estimate the Yield and Quality of Table Grapes. Agriculture 2018, 8, 94. [CrossRef]

39. Kavvadias, A.; Psomiadis, E.; Chanioti, M.; Gala, E.; Michas, S. Precision agriculture-Comparison and evaluation of innovative very high resolution (UAV) and LandSat data. In Proceedings of the CEUR Workshop Proceedings, Brussels, Belgium, 27 March 2015; Volume 1498.

40. Bellvert, J.; Zarco-Tejada, P.J.; Marsal, J.; Girona, J.; González-Dugo, V.; Fereres, E. Vineyard irrigation scheduling based on airborne thermal imagery and water potential thresholds. Aust. J. Grape Wine Res. 2016, 22, 307-315. [CrossRef]

41. Hall, A.; Louis, J.P.; Lamb, D.W. Low-resolution remotely sensed images of winegrape vineyards map spatial variability in planimetric canopy area instead of leaf area index. Aust. J. Grape Wine Res. 2008, 14, 9-17. [CrossRef]

42. Xue, J.; Su, B. Significant remote sensing vegetation indices: A review of developments and applications. J. Sens. 2017, 2017, 1353691. [CrossRef]

43. Rouse, J.W.; Haas, R.H.; Schell, J.A.; Deering, W.D. Monitoring vegetation systems in the Great Plains with ERTS. In Proceedings of the Third Earth Resources Technology Satellite-1 Symposium, Washington, DC, USA, 10-14 December 1973; Freden, S.C., Mercanti, E.P., Becker, M., Eds.; NASA: Washington, DC, USA, 1974; pp. 309-317.

44. Hatfield, J.L.; Gitelson, A.A.; Schepers, J.S.; Walthall, C.L. Application of spectral remote sensing for agronomic decisions. Agron. J. 2008, 100, S-117-S-131. [CrossRef]

45. Magarreiro, C.; Gouveia, C.; Barroso, C.; Trigo, I. Modelling of Wine Production Using Land Surface Temperature and FAPARThe Case of the Douro Wine Region. Remote Sens. 2019, 11, 604. [CrossRef]

46. Borgogno-Mondino, E.; de Palma, L.; Novello, V. Investigating Sentinel 2 Multispectral Imagery Efficiency in Describing Spectral Response of Vineyards Covered with Plastic Sheets. Agronomy 2020, 10, 1909. [CrossRef]

47. Stroppiana, D.; Pepe, M.; Boschetti, M.; Crema, A.; Candiani, G.; Giordan, D.; Baldo, M.; Allasia, P.; Monopoli, L. Estimating Crop Density From Multi-Spectral Uav Imagery in Maize Crop. Int. Arch. Photogramm. Remote Sens. Spat. Inf. Sci. 2019, XLII-2/W13, 619-624. [CrossRef]

48. Morlin Carneiro, F.; Angeli Furlani, C.E.; Zerbato, C.; Candida de Menezes, P.; da Silva Gírio, L.A.; Freire de Oliveira, M. Comparison between vegetation indices for detecting spatial and temporal variabilities in soybean crop using canopy sensors. Precis. Agric. 2020, 21, 979-1007. [CrossRef]

49. Peloponnese Wine Region, Greece / Winetourism. Available online: https://www.winetourism.com/wine-region/peloponnese/ (accessed on 24 March 2021).

50. Dobrowski, S.Z.; Ustin, S.; Wolpert, J.A. Remote estimation of vine canopy density in vertically shoot-positioned vineyards: Determining optimal vegetation indices. Aust. J. Grape Wine Res. 2002, 8, 117-125. [CrossRef]

51. Ballesteros, R.; Intrigliolo, D.S.; Ortega, J.F.; Ramírez-Cuesta, J.M.; Buesa, I.; Moreno, M.A. Vineyard yield estimation by combining remote sensing, computer vision and artificial neural network techniques. Precis. Agric. 2020, 21, 1242-1262. [CrossRef]

52. Kottek, M.; Grieser, J.; Beck, C.; Rudolf, B.; Rubel, F. World map of the Köppen-Geiger climate classification updated. Meteorol. Z. 2006, 15, 259-263. [CrossRef]

53. Psomiadis, E.; Diakakis, M.; Soulis, K.X. Combining SAR and Optical Earth Observation with Hydraulic Simulation for Flood Mapping and Impact Assessment. Remote Sens. 2020, 12, 3980. [CrossRef]

54. Taylor, J.; Tisseyre, B.; Praat, J.-P. Information and Technology for Sustainable Fruit and Vegetable Production Bottling Good Information: Mixing Tradition and Technology in vineyards. In Proceedings of the Information and Technology for Sustainable Fruit and Vegetable Production, Montpellier, France, 12-16 September 2005; pp. 719-736.

55. Bonilla, I.; Martínez, D.; Toda, F.; Martínez-Casasnovas, J.A. Grape quality assessment by airborne remote sensing over three years. Precis. Agric. 2013, 611-615. [CrossRef]

56. Kazmierski, M.; Glemas, P.; Rousseau, J.; Tisseyre, B. Temporal stability of within-field patterns of ndvi in non irrigated mediterranean vineyards. J. Int. Sci. Vigne Vin. 2011, 45, 61-73. [CrossRef]

57. Sozzi, M.; Kayad, A.; Marinello, F.; Taylor, J.; Tisseyre, B. Comparing vineyard imagery acquired from Sentinel-2 and Unmanned Aerial Vehicle (UAV) platform. OENO One 2020, 54, 189-197. [CrossRef]

58. Piragnolo, M.; Lusiani, G.; Pirotti, F. Comparison of Vegetation Indices from RPAS and Sentinel-2 Imagery for Detecting Permanent Pastures. ISPRS Int. Arch. Photogramm. Remote Sens. Spat. Inf. Sci. 2018, XLII-3, 1381-1387. [CrossRef]

59. Tagarakis, A.; Liakos, V.; Fountas, S.; Koundouras, S.; Gemtos, T.A. Management zones delineation using fuzzy clustering techniques in grapevines. Precis. Agric. 2013, 14, 18-39. [CrossRef]

60. Efthimiou, N.; Psomiadis, E.; Panagos, P. Fire severity and soil erosion susceptibility mapping using multi-temporal Earth Observation data: The case of Mati fatal wildfire in Eastern Attica, Greece. Catena 2020, 187, 104320. [CrossRef]

61. Barnes, E.M.; Clarke, T.R.; Richards, S.E.; Colaizzi, P.D.; Haberland, J.; Kostrzewski, M.; Waller, P.; Choi, C.; Riley, E.; Thompson, T. Coincident detection of crop water stress, nitrogen status and canopy density using ground-based multispectral data. In Proceedings of the Fifth International Conference on Precision Agriculture and Other Resource Management, Bloom, MN, USA, 16-19 July 2000. 
62. Lu, J.; Miao, Y.; Shi, W.; Li, J.; Yuan, F. Evaluating different approaches to non-destructive nitrogen status diagnosis of rice using portable RapidSCAN active canopy sensor. Sci. Rep. 2017, 7, 14073. [CrossRef]

63. Bonfil, D.J. Wheat phenomics in the field by RapidScan: NDVI vs. NDRE. Isr. J. Plant Sci. 2017, 64, 41-54. [CrossRef]

64. Qi, J.; Chehbouni, A.; Huete, A.R.; Kerr, Y.H.; Sorooshian, S. A modified soil adjusted vegetation index. Remote Sens. Environ. 1994, 48, 119-126. [CrossRef]

65. Gao, B.C. NDWI-A normalized difference water index for remote sensing of vegetation liquid water from space. Remote Sens. Environ. 1996, 58, 257-266. [CrossRef]

66. Gitelson, A.A.; Kaufman, Y.J.; Stark, R.; Rundquist, D. Novel algorithms for remote estimation of vegetation fraction. Remote Sens. Environ. 2002, 80, 76-87. [CrossRef]

67. Carlson, T.N.; Gillies, R.R.; Perry, E.M. A method to make use of thermal infrared temperature and NDVI measurements to infer surface soil water content and fractional vegetation cover. Remote Sens. Rev. 1994, 9, 161-173. [CrossRef]

68. Pickett-Heaps, C.A.; Canadell, J.G.; Briggs, P.R.; Gobron, N.; Haverd, V.; Paget, M.J.; Pinty, B.; Raupach, M.R. Evaluation of six satellite-derived Fraction of Absorbed Photosynthetic Active Radiation (FAPAR) products across the Australian continent. Remote Sens. Environ. 2014, 140, 241-256. [CrossRef]

69. Qin, J.; Zhao, L.; Chen, Y.; Yang, K.; Yang, Y.; Chen, Z.; Lu, H. Inter-comparison of spatial upscaling methods for evaluation of satellite-based soil moisture. J. Hydrol. 2015, 523, 170-178. [CrossRef]

70. Minasny, B.; McBratney, A.B.; Whelan, B.M. VESPER Version 1.6; Sydney University Press: Sydney, Austalia, 2005.

71. Fiorillo, E.; Crisci, A.; De Filippis, T.; Di Gennaro, S.F.; Di Blasi, S.; Matese, A.; Primicerio, J.; Vaccari, F.P.; Genesio, L. Airborne high-resolution images for grape classification: Changes in correlation between technological and late maturity in a Sangiovese vineyard in Central Italy. Aust. J. Grape Wine Res. 2012, 18, 80-90. [CrossRef]

72. Taylor, J.A.; Bates, T.R. A discussion on the significance associated with Pearson's correlation in precision agriculture studies. Precis. Agric. 2013, 14, 558-564. [CrossRef]

73. STATGRAPHICS Version 16. Available online: http://www.statvision.com/version16.htm (accessed on 21 December 2020).

74. Ayalew, L.; Yamagishi, H. The application of GIS-based logistic regression for landslide susceptibility mapping in the KakudaYahiko Mountains, Central Japan. Geomorphology 2005, 65, 15-31. [CrossRef]

75. Youssef, A.M.; Al-Kathery, M.; Pradhan, B. Landslide susceptibility mapping at Al-Hasher area, Jizan (Saudi Arabia) using GIS-based frequency ratio and index of entropy models. Geosci. J. 2015, 19, 113-134. [CrossRef]

76. Akgun, A.; Sezer, E.A.; Nefeslioglu, H.A.; Gokceoglu, C.; Pradhan, B. An easy-to-use MATLAB program (MamLand) for the assessment of landslide susceptibility using a Mamdani fuzzy algorithm. Comput. Geosci. 2012, 38, 23-34. [CrossRef]

77. Gatti, M.; Squeri, C.; Kleshcheva, E.; Garavani, A.; Vincini, M.; Poni, S. Studying spatial and temporal variability of a "Barbera" vineyard with traditional and precision approaches. Acta Hortic. 2020, 1279, 247-254. [CrossRef]

78. Reynolds, A.G.; Lee, H.-S.; Dorin, B.; Brown, R.; Jollineau, M.; Shemrock, A.; Crombleholme, M.; Jobin Poirier, E.; Zheng, W.; Gasnier, M.; et al. Mapping Cabernet Franc vineyards by unmanned aerial vehicles (UAVs) for variability in vegetation indices, water status, and virus titer. E3S Web Conf. 2018, 50, 02010. [CrossRef]

79. Primicerio, J.; Di Gennaro, S.F.; Fiorillo, E.; Genesio, L.; Lugato, E.; Matese, A.; Vaccari, F.P. A flexible unmanned aerial vehicle for precision agriculture. Precis. Agric. 2012, 13, 517-523. [CrossRef]

80. Henry, D.; Aubert, H.; Veronese, T. Proximal Radar Sensors for Precision Viticulture. IEEE Trans. Geosci. Remote Sens. 2019, 57, 4624-4635. [CrossRef]

81. Stamatiadis, S.; Taskos, D.; Tsadilas, C.; Christofides, C.; Tsadila, E.; Schepers, J.S. Relation of Ground-Sensor Canopy Reflectance to Biomass Production and Grape Color in Two Merlot Vineyards. Am. J. Enol. Vitic. 2006, 57, 415-422.

82. Martínez-Beltrán, C.; Jochum, M.A.O.; Calera, A.; Meliá, J. Multisensor comparison of NDVI for a semi-arid environment in Spain. Int. J. Remote Sens. 2009, 30, 1355-1384. [CrossRef]

83. Mathews, A.J. Object-based spatiotemporal analysis of vine canopy vigor using an inexpensive unmanned aerial vehicle remote sensing system. J. Appl. Remote Sens. 2014, 8, 085199. [CrossRef]

84. Acevedo-Opazo, C.; Tisseyre, B.; Guillaume, S.; Ojeda, H. The potential of high spatial resolution information to define withinvineyard zones related to vine water status. Precis. Agric. 2008, 9, 285-302. [CrossRef]

85. Sun, L.; Gao, F.; Anderson, M.; Kustas, W.; Alsina, M.; Sanchez, L.; Sams, B.; McKee, L.; Dulaney, W.; White, W.; et al. Daily Mapping of 30 m LAI and NDVI for Grape Yield Prediction in California Vineyards. Remote Sens. 2017, 9, 317. [CrossRef]

86. Johnson, L.F. Temporal stability of an NDVI-LAI relationship in a Napa Valley vineyard. Aust. J. Grape Wine Res. 2003,9 , 96-101. [CrossRef]

87. Kotsaki, E.; Reynolds, A.G.; Brown, R.; Jollineau, M.; Lee, H.S.; Aubie, E. Proximal sensing and relationships to soil and vine water status, yield, and berry composition in ontario vineyards. Am. J. Enol. Vitic. 2020, 71, 114-131. [CrossRef]

88. Costa, B.R.S.; Oldoni, H.; Rocha, R.C.; Bassoi, L.H. Delimitation of homogeneous zones in vineyards using geostatistics and multivariate analysis of different vegetation indices. Eng. Agric. 2019, 39, 13-22. [CrossRef]

89. Matese, A.; Toscano, P.; Di Gennaro, S.; Genesio, L.; Vaccari, F.; Primicerio, J.; Belli, C.; Zaldei, A.; Bianconi, R.; Gioli, B. Intercomparison of UAV, Aircraft and Satellite Remote Sensing Platforms for Precision Viticulture. Remote Sens. 2015, 7, $2971-2990$. [CrossRef] 
90. Erena, M.; Montesinos, S.; Portillo, D.; Alvarez, J.; Marin, C.; Fernandez, L.; Henarejos, J.M.; Ruiz, L.A. Configuration and Specifications of an Unmanned Aerial Vehicle for Precision Agriculture. In Proceedings of the International Archives of the Photogrammetry, Remote Sensing and Spatial Information Sciences-XXIII ISPRS Congress, Prague, Chech Republic, 12-19 July 2016; pp. 809-816.

91. Spachos, P.; Gregori, S. Integration of Wireless Sensor Networks and Smart UAVs for Precision Viticulture. IEEE Internet Comput. 2019, 23, 8-16. [CrossRef]

92. García-Estévez, I.; Quijada-Morín, N.; Rivas-Gonzalo, J.C.; Martínez-Fernández, J.; Sánchez, N.; Herrero-Jiménez, C.M.; EscribanoBailón, M.T. Relationship between hyperspectral indices, agronomic parameters and phenolic composition of Vitis vinifera cv Tempranillo grapes. J. Sci. Food Agric. 2017, 97, 4066-4074. [CrossRef] 